Article

\title{
Application of Combined Geophysical Methods for the Examination of a Water Dam Subsoil
}

\author{
Tomisław Gołębiowski ${ }^{1}$, Bogdan Piwakowski ${ }^{2}$, Michał Ćwiklik ${ }^{1, * \mathbb{D}}$ and Antoni Bojarski ${ }^{1}$ \\ 1 Faculty of Environmental and Power Engineering, Cracow University of Technology, Warszawska Str. 24, \\ 31-155 Cracow, Poland; tgolebiowski@pk.edu.pl (T.G.); bojarski@pk.edu.pl (A.B.) \\ 2 Ecole Centrale de Lille-Institute d'Electronique, Microelectronique \& Nanotechnologies Cité Scientifique CS 20048, \\ CEDEX, 59-651 Villeneuve d'Ascq, France; bogdan.piwakowski@centralelille.fr \\ * Correspondence: michal.cwiklik@doktorant.pk.edu.pl
}

\section{check for}

updates

Citation: Gołębiowski, T.; Piwakowski, B.; Ćwiklik, M.;

Bojarski, A. Application of Combined

Geophysical Methods for the

Examination of a Water Dam Subsoil.

Water 2021, 13, 2981. https: //

doi.org/10.3390/w13212981

Received: 16 July 2021

Accepted: 7 October 2021

Published: 22 October 2021

Publisher's Note: MDPI stays neutral with regard to jurisdictional claims in published maps and institutional affiliations.

Copyright: (c) 2021 by the authors. Licensee MDPI, Basel, Switzerland. This article is an open access article distributed under the terms and conditions of the Creative Commons Attribution (CC BY) license (https:// creativecommons.org/licenses/by/ $4.0 /)$.

\begin{abstract}
The paper presents the results of geophysical measurements that were carried out in the vicinity of the water dam/water reservoir supplying the city of Bielsko-Biala with drinking water. The measurements were performed in order to non-invasively detect faults, fractured zones and areas filled with breccia, which may be, at the same time, a preferential path of groundwater flow. The aforementioned factors influence the stability of the dam. The general identification of the examined media was realized by the electrical resistivity tomography method. The ERT surveys were supplemented by capacitively-coupled resistivity. The electrical methods allowed them to recognize geological settings, indicate possible fault locations, and point out the fault plane as a path of water flow. The ground penetrating radar method detected fractured and filled water areas and underground water paths in the dam's forefield as a result of the method's very high resolution. The high resolution seismic reflection method provided a clear and high resolution image of the relatively deep geological structure and verified a location and the run of the faults. In general, the complex geophysical-geological interpretation enabled classification of the unconsolidated/fractured zones associated with faults as a place where the erosion process is the most intense and can bring danger on the dam. Finally, it was confirmed that the area should be the subject of geophysical monitoring.
\end{abstract}

Keywords: water dam; hydrotechnical construction; geophysical methods; water flow

\section{Introduction}

Hydro engineering constructions are crucial for protecting human lives and activities. Regrettably, the technical condition of this type of construction in many countries is not satisfactory. As an example, the statistics from Poland show that over $60 \%$ of the whole levees is over 50 years old [1]. In the present case, the water dam is almost 100 years old and was built in an area with a complex geological structure (Carpathian flysch) [2-4]. Moreover, the area has not been properly recognized from a geological point of view. The dam construction is at risk, as evidenced by the constantly appearing new cracks and changing levels in piezometers (during the measurements session the water level decreasing). In addition, recently (August 2021) the water level in the piezometers has been increasing and the phenomena is correlated with the rainwater afflux from the nearby mountains. These factors show how the hydrogeological situation is complex. All things considered, in our research we perform a general geological recognition with the use of noninvasive geophysical methods. To choose the optimal geophysical method, we conducted literature research. Secondly, we want to verify what is the reason for the change in the water level. We consider the following scenario: (1) water flows from the Szyndzielnia pick (Figure 1B,C), (2) water flows under the dam construction. The first case has weaker sides. First of all, the water flow from the mentioned mountain is not able to cause such changes (cracks, etc.) in the dam construction. The second scenario is the worst-case scenario. The question is if there is any obvious path of water flow or maybe flowing is realizing through 
the whole porous/cracking medium. The following question concerns both cases. It is also possible that both scenarios are realized at the same time.

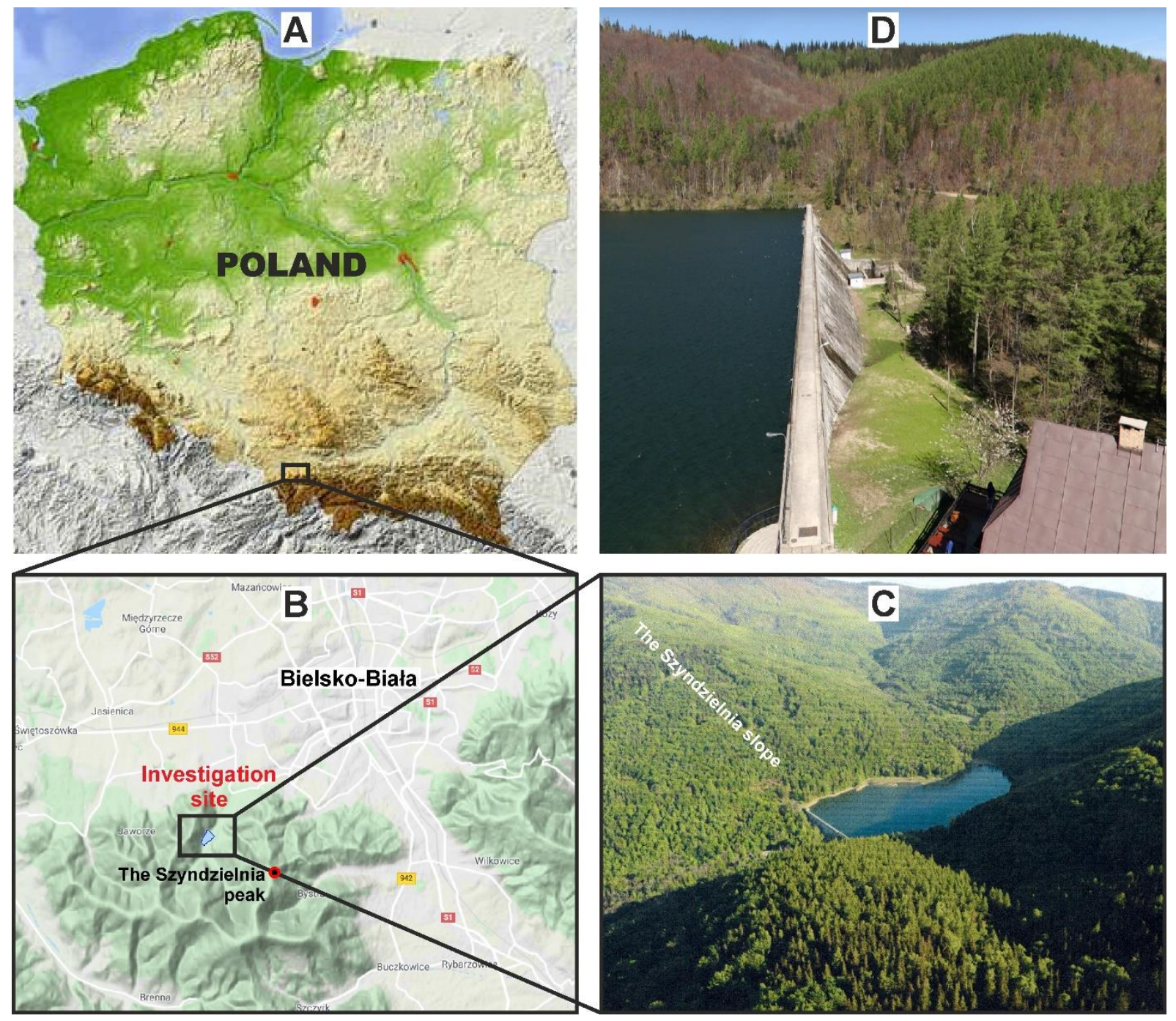

Figure 1. (A) General location of the investigation site; (B) location of water dam near the city of Bielsko-Biala (district: Wapienica )—www.google.pl/maps, accessed on 1 October 2021; (C) aerial view of water dam [5]; (D) site of geophysical survey in front of water dam [4].

In the next stage the literature study was performed. In general, the paper touching on the topic of applied geophysical methods to recognize internal structure of the dams and its vicinity is not so wide as in the levee case.

On the whole, in the available papers there are a few methods that may be applied for the examination of hydrotechnical constructions and their subsoil. Electrical and electromagnetic methods were predominantly applied for this purpose, as well as seismic techniques. Herein, the following geophysical methods should be mentioned: standard (i.e., short-offset reflection profiling) ground penetrating radar (GPR) method [5,6], nonstandard GPR surveys [7-11] where the different antennas orientation can be used to provide a more reliable picture of the internal structure of the dam or also can be use the GPR attributes to pick weak zones in the studied medium. One of the most used methods in this case is also electrical resistivity tomography (ERT) called also the resistivity imaging (RI). In most cases 2D ERT technique was applied [12,13]. It is worth mentioning, the prior mentioned methods are commonly applied techniques and the most effective to study the dam vicinity. The electromagnetic profiling (EMP) method also called the ground 
conductivity meter (GCM) is less popular than the previous one and It uses to relatively fast recognition of the levee [5]. Occasionally, other geophysical methods were used, e.g., seismic surveys, i.e., reflection, refraction and MASW measurements [14], microgravimetric technique [15], very low frequency (VLF) method, radio-magnetotelluric (MT) method, infrared (IR) method, self-potentials (SP) method, acoustic emission (AE) [16] and LiDAR technique $[6,17]$.

Based on the performed analysis, for our study we choose the GPR, ERT and seismic method. We also planned to test capacitively coupled resistivity method (CCR), which in the literature is considered as the method gaining popularity. We also spotted that the problem is the introduced methods are very often used separately. That provides an additional ambiguity to the results of the geophysical research. To avoid this, a comprehensive geophysical approach should be used, involving a few geophysical methods that complement each other.

\section{Study Area}

The following paragraph presents general information concerning the water dam and its subsoil; this information was gathered on the basis of analysis of reports prepared by Oboza [3] and Bojarski [2].

The water dam was built on the streams called Wapienica and Barbara, before World War II and its exploitation began in 1933. It was built to supply water to the city of BielskoBiala (Figure 1B). The body of dam, which has a length of $312 \mathrm{~m}$, is made of concrete (Figure 1D), however the last $60 \mathrm{~m}$ of the water dam (Figure 2) was constructed as a concrete core earth dam. The height of the dam near the geophysical profiles equals $19 \mathrm{~m}$ measuring from the terrain surface, but the total height of the dam equals $27 \mathrm{~m}$ (Figure 3A). The body of dam consists of 17 concrete blocks (Figure 3B-only a small proportion of the blocks were shown) with dilatation gaps between several blocks; the gaps are sealed with copper plates and bitumen. The width of the dam at the base is $20 \mathrm{~m}$ and $3 \mathrm{~m}$ in the top part (Figure 3A).

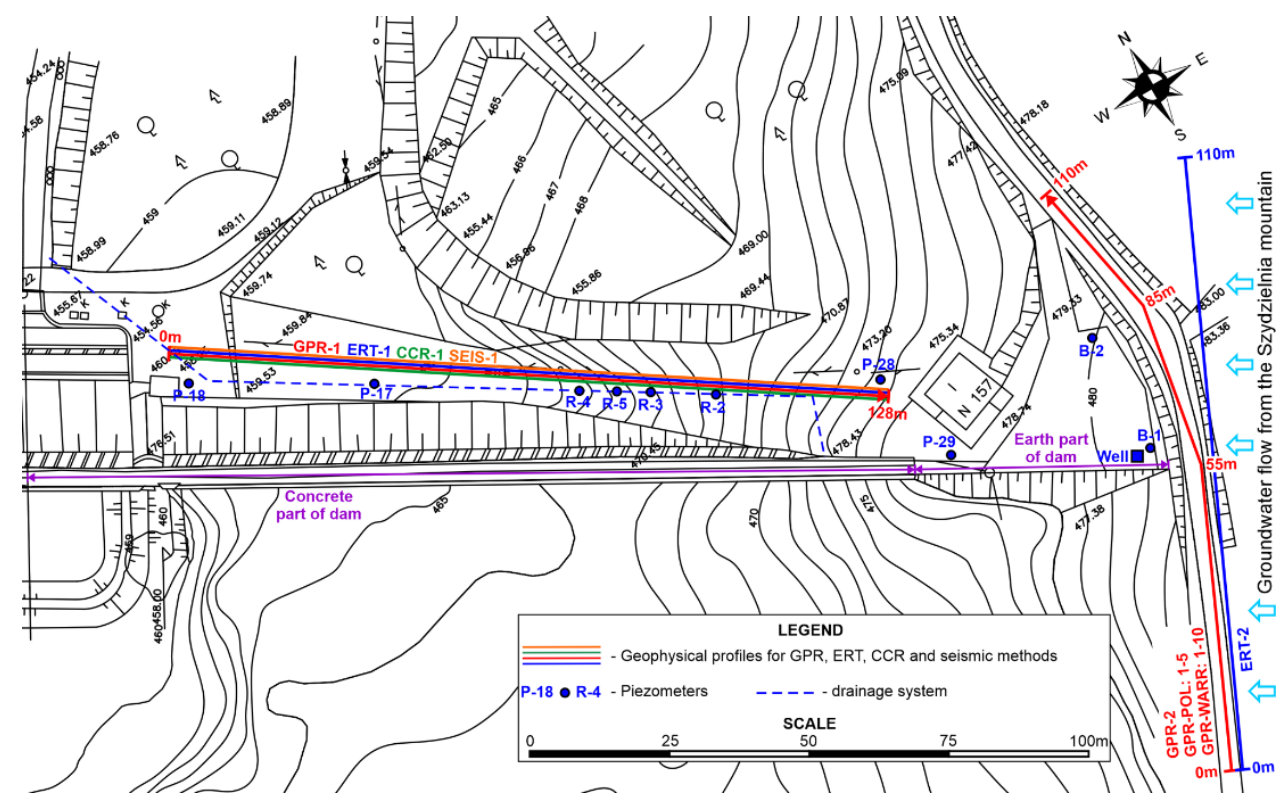

Figure 2. Horizontal view of the investigation site and project of geophysical profiles; base map [2]. 


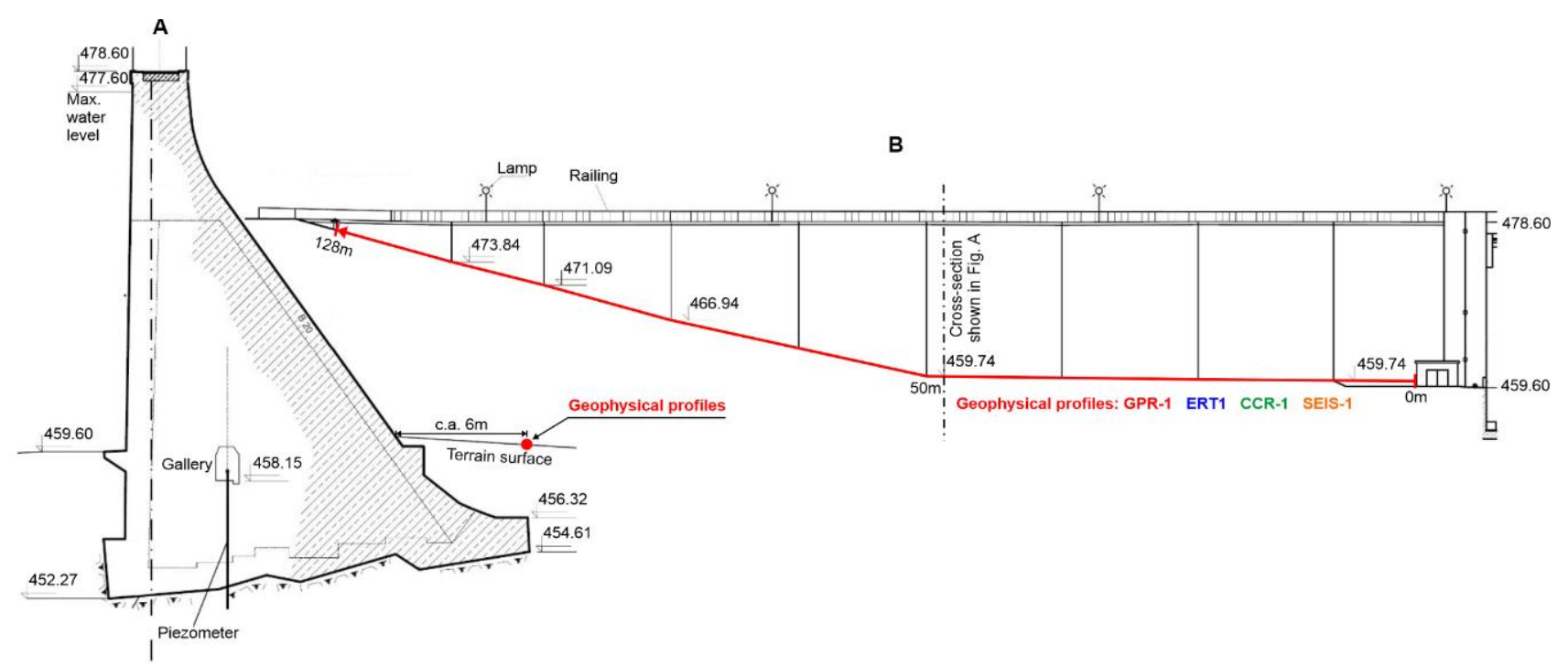

Figure 3. (A) Cross-section of the dam in central part of geophysical profiles [2]; (B) the south-eastern part of dam-concrete blocks and geophysical profiles were shown.

The identification of geological structures located under the water dam was started in part before World War I and resumed before the Second World War, using techniques typical to those times, i.e., general geological charting, excavations/trenches and several boreholes. In the area of the dam, under the thin layer of soil and weathered diluvial sediments, sandstones and mudstone shales of the Carpathian flysch were detected. The aforementioned formations were created in the Cretaceous period and they sink towards the south-western direction with an angle of 15-20 degrees. In the central and northwestern part of the dam, thick layers of sandstones occur which are interbedded by thin layers of shale. The most complicated geological settings occur in the south-eastern part of the dam, where the geological medium was strongly deformed by tectonic phenomena. This, in turn, caused highly fractured rocks and a lot of rock breccia occur in the subsoil of the dam faults (Figure 4). This resulted in an easy flow of groundwater along the preferential migration paths from the Szyndzielnia mountain (Figure 1C) to the region of the south-eastern part of the dam (Figure 2). As a result of the underground water flow, a suffusion process appeared and instability of the slope in the south-eastern part of the dam was observed (Figure 2 - the region around and below the building named N-157). A complicated geological design resulted in the last $60 \mathrm{~m}$ of the dam being constructed as a concrete core earth dam (Figure 2) and the underground water in this part of dam were captured by the drainage system and discharged into the reservoir.

Between 1933 and the 1990s, only minor repairs of the dam were carried out. During one of the repair periods (1962-1967), an injection of liquid cement into the fissures existing in the body of the dam and bitumen was inserted into the dilatation gaps. General renovation of the dam was conducted between the years of 1991-2017 in several stages. During of one of the renovation stages, between 1997-2000, cracks, micro-caverns, and zones with higher porosity existing in the top part of the dam which were filled by an injection of liquid cement. For this purpose, boreholes drilled from the top of the dam with a constant distance of approximately $0.7 \mathrm{~m}$ were prepared. Additionally, boreholes drilled from the gallery (Figure 3A) were prepared for the injection of filling material (liquid mixture of cement and slag) into the geological medium with a depth of approximately $12 \mathrm{~m}$ under the basement of the water dam. The injection carried out in the body of the dam was monitored using the seismic tomography technique [18] and the result of filling the fractures located under the dam was analysed by GPR surveys carried out from the gallery (Figure 3A). The high-resolution GPR technique was also applied in 2019 for the detection of the fissures and higher porosity zones in the body of dam, which were not 
filled in 1997. The complex interpretation of seismic and GPR measurements performed for the examination of the body of dam will be presented in another paper. The information presented above, concerning the injection of different materials into the body of dam is important, because, most likely, a part of these materials got through into the subsoil of the dam in the region of the geophysical surveys (Figure 2-region of profiles marked with "1").

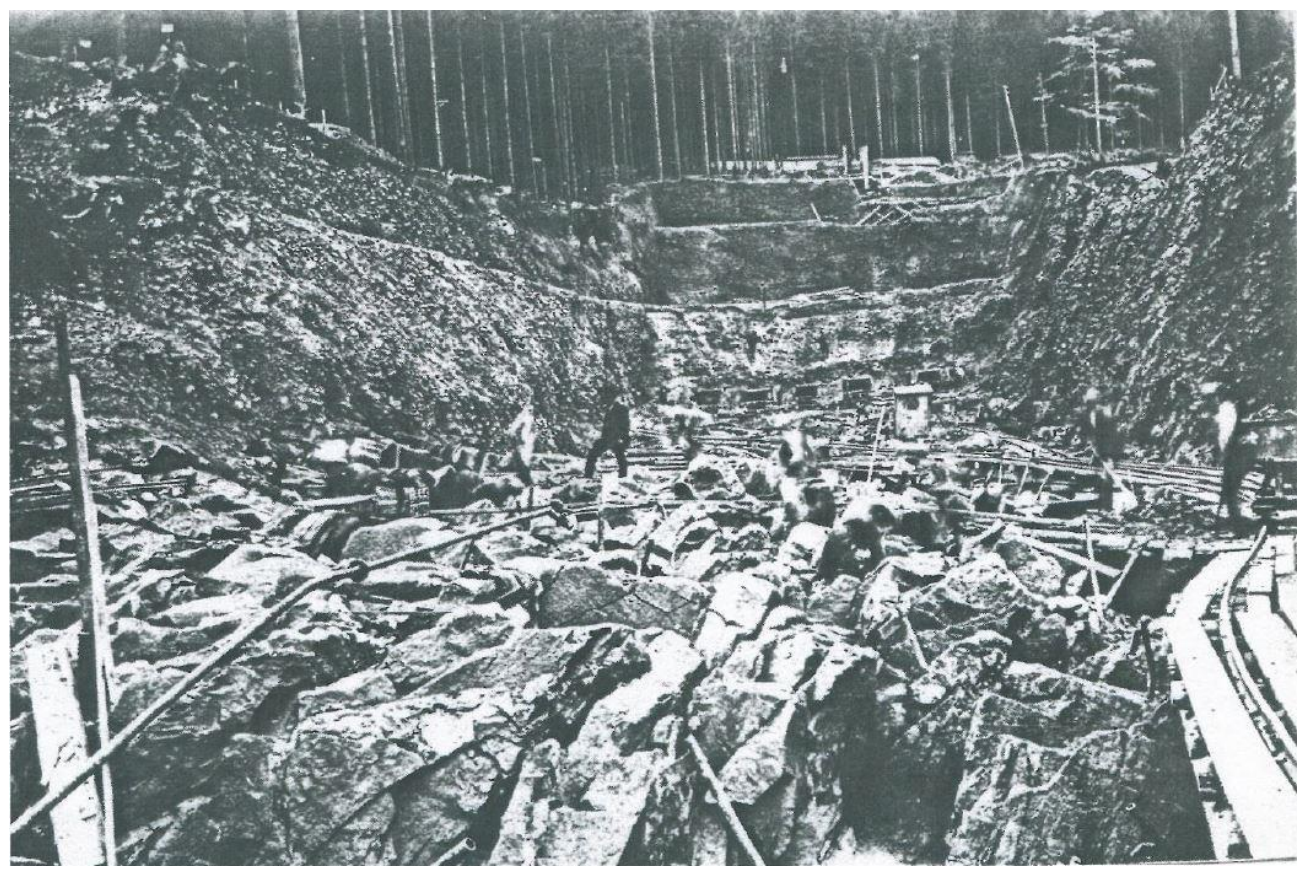

Figure 4. Excavation made in the slope of the Szyndzielnia mountain (the south-eastern part of the dam) during the building of the water dam in Wapienica site [4].

The boreholes drilled for filling the fractures in the dam generated additional information from the geological structures located directly under the dam, i.e., to the depth of 36-46 m (counting from the top of the dam). A thick layer of yellow and yellow-grey fractured sandstone was discovered, while the fractures were very often filled with clay.

In the 1990s, an intensification of the suffusion process and the outflow of underground water to the surface was observed at the slope in the south-eastern part of the dam (Figure 1D, Figure 2-below the building named N-157). Therefore, in the years 2001-2002, in the earth part of the dam (Figure 2), an injection of filling material into the fractures was performed. At the same time, cleaning of the drainage system located in this part of the dam was carried out. These means only partly solved the problems caused by suffusion. Therefore, in 2006 an additional drainage system was designed and fitted below the building named N-157 (Figure 2). This drainage system gathered the surface and underground waters in front of the dam and drains the waters to the Wapienica stream, below the dam. This additional drainage system is important because a part of the geophysical surveys were carried out near this system (Figure 2-profiles marked " 1 "). The aforementioned drainage system consists of several vertical boreholes with a diameter of $0.6 \mathrm{~m}$, filled with gravel, which are connected to each other. Unfortunately, the existing of the pre-war drainage system as well as the additional drainage system did not reduce markedly the suffusion process and the geological medium in the south-eastern part of the water dam is still unstable.

In the next section, selected results of geophysical surveys carried out in the bottom part of the slope of the Szyndzielnia mountain (Figure 1C,D) and in the area of the southeastern part of the water dam (Figure 2) are presented. 


\section{Results of Geophysical Investigations}

As mentioned in the introduction, the geophysical methods were applied for noninvasive detection of faults, fractured zones and areas filled with breccia in the subsoil of the water dam. The presence of such features in the rock-mass causes creation of preferential paths of groundwater flow which strongly influence the instability of the geological medium as well as underground and surface technical infrastructure plus buildings.

In this section, the results of the preliminary geophysical surveys carried out along the profiles designed alongside and perpendicularly to the slope (Figure 2) are presented. For surveys, the following complementary methods were chosen: two wave-field methods, i.e., Ground Penetrating Radar (GPR) and seismic techniques and two geoelectrical methods, i.e., Electrical Resistivity Tomography (ERT) and Capacitively-Coupled Resistivity (CCR) technique.

\subsection{GPR Surveys}

The short-offset reflection surveys were carried out along the profiles GPR-1 and GPR-2 (Figure 2), however they were preceded by the WARR measurements performed along the 10-m-long profiles named: GPR-WARR-1 ... GPR-WARR-10, designed alongside profile GPR-2 (Figure 2).

All terrain surveys were carried out with the use of VIY georadar system (produced by Transient Technologies-www.viy.ua, accessed on 1 October 2021). A standard (i.e., co-pole) orientation of the antennae with frequency of $125 \mathrm{MHz}$ (max. depth penetration of approximately $15 \mathrm{~m}$ and mean resolution in dry sandstone of approximately $0.25 \mathrm{~m}$ ) and $70 \mathrm{MHz}$ (max. depth penetration of approximately $30 \mathrm{~m}$ and mean resolution in dry sandstone of approximately $0.5 \mathrm{~m}$ ) was applied. Traces were recorded with a constant distance interval of $\Delta x=0.1 \mathrm{~m}$ (for $125 \mathrm{MHz}$ antenna) and $\Delta \mathrm{x}=0.2 \mathrm{~m}$ (for $70 \mathrm{MHz}$ antenna). To improve the signal/noise ratio, 8-times stacking was applied during data acquisition.

All radargrams presented in the paper were subjected to standard signal processing using ReflexW software [19]; a detailed description of radargram processing may be found in literature [19-21].

Along profile GPR-2, additional GPR reflection surveys with different antennae orientations (and consequently with different polarizations of electromagnetic wave) were performed; the profiles for such surveys were named: GPR-POL-1 ... GPR-POL-5 (Figure 2). For radargrams recorded along these profiles, more advanced processing was applied-the following procedures were used: signal declipping, phase correlation, 1D median filter, dewowing, DC shift, analysis of polarity, Butterworth time-depended filtration, energy decay analysis, background removal, spectral whitening, 2D average filtration, envelopes (counted from Hilbert transform), morphology filtration. Detailed descriptions of the above-mentioned procedures may be found in $[19,22]$.

The amplitudes on the radargrams were normalised to a maximum amplitude of the Direct Air Wave which allowed for a comparative, qualitative interpretation.

From among 10 WARR measurements, only 3 delivered satisfactory recordings (Figure 5). The velocity of the Direct Ground Wave (DGW) varied from $0.065 \mathrm{~m} / \mathrm{ns}$ to $0.09 \mathrm{~m} / \mathrm{ns}$ and the velocity of the Reflected Wave (RW) varied from $0.045 \mathrm{~m} / \mathrm{ns}$ to $0.065 \mathrm{~m} / \mathrm{ns}$. Finally, for the time-depth conversion of radargrams, a constant mean velocity of electromagnetic wave equal to $0.066 \mathrm{~m} / \mathrm{ns}$ was assumed. It should be noted that the velocity for consolidated, dry sandstone is equal to $0.15 \mathrm{~m} / \mathrm{ns}$; the estimation from the WARR velocities (i.e., $0.045-0.065 \mathrm{~m} / \mathrm{ns}$ ) shows that the rock mass (i.e., blocks of flysch sandstones) is fractured and fissures are filled with water or are colmatated with wet clay. 

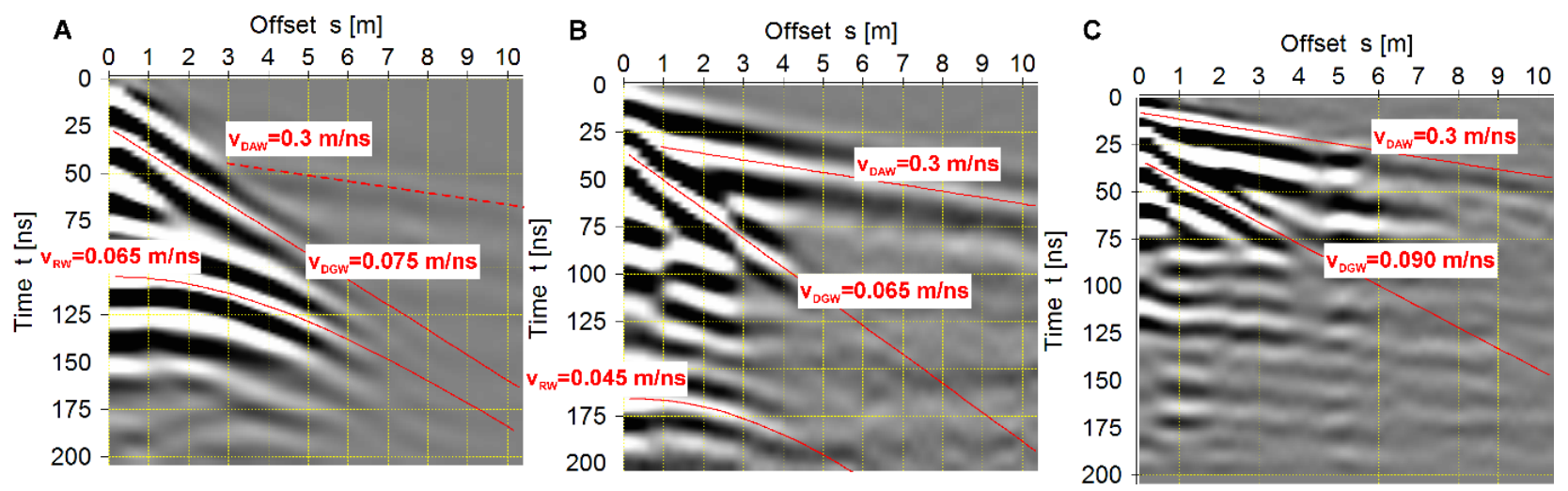

Figure 5. Selected results of WARR measurements carried out along profile GPR-2: (A) from 0m to 10m of profile; (B) from $40 \mathrm{~m}$ to $50 \mathrm{~m}$ of profile; (C) from $90 \mathrm{~m}$ to $100 \mathrm{~m}$ of profile.

Considering, geologically, that rock mass in the investigation site is built of thick blocks (layers) of sandstones which are interbedded by thin layers of shale, the following interpretation model was assumed: (a) effects generated in radargrams by solid sandstone were the background for interpretation, (b) sandstone was covered by weathered material and soil which should generate effects in radargrams with higher amplitudes to the depth of a few meters, (c) layers of shales should generate in radargrams thin, linear effects with mean amplitudes, (d) all high-amplitudes anomalies in radargrams should depict the dry or water or wet clay filled fractures existed in sandstone.

In the next step of terrain measurements, GPR surveys with the use of $125 \mathrm{MHz}$ (Figure 6A) and $70 \mathrm{MHz}$ antennae (Figure 6B) were performed along profile GPR-1.

In Figure 6A, high-amplitude anomalies can be observed to the depth of $1 \mathrm{~m}$, regionally to $2 \mathrm{~m}$, and they depict heterogeneities in the soil and weathered sandstone. These heterogeneities may be correlated with the zones of higher porosity and water permeability and, in such zones, easy infiltration of water from precipitation and melted snow to the geological medium can be observed. The high value amplitudes in the near surface zones reveal that these zones are saturated by water, especially from $\mathrm{x}=40 \mathrm{~m}$ to $\mathrm{x}=70 \mathrm{~m}$ and between $\mathrm{x}=83$ and $104 \mathrm{~m}$, as well as from $\mathrm{x}=117 \mathrm{~m}$ to $\mathrm{x}=128 \mathrm{~m}$. Most important for the underground water flow are the GPR anomalies located in greater depths-in Figure 6A such a water saturated zone is easily noticed between $x=83 \mathrm{~m}$ and $\mathrm{x}=104 \mathrm{~m}$. Other anomalies with higher amplitudes located along the whole profile between the depths of $2 \mathrm{~m}$ and $6 \mathrm{~m}$ may be correlated with the fractures filled with different amount of air, water and clay.

In Figure 6B, high-amplitude anomalies were recorded in the near surface zone, to the depth of approximately $2 \mathrm{~m}$, and these anomalies were interpreted above. At greater depths, interesting anomalies indicating water or wet clay saturated zones were noticed between $x=0 \mathrm{~m}$ and $\mathrm{x}=13 \mathrm{~m}, \mathrm{x}=37$ and $\mathrm{x}=85 \mathrm{~m}$, as well as $\mathrm{x}=115 \mathrm{~m}$ and $\mathrm{x}=128 \mathrm{~m}$. Other anomalies with higher amplitudes may be correlated with fractured sandstone.

It is worth noting that in Figure 6A the most important anomaly was recorded between $x=83 \mathrm{~m}$ and $\mathrm{x}=104 \mathrm{~m}$ but in Figure $6 \mathrm{~B}$ a decrease in amplitudes in this region is instead observed. This phenomenon may be explained by the fact that the measurements using a $125 \mathrm{MHz}$ antenna were carried out a few days before the measurements using the $70 \mathrm{MHz}$ antenna, and as water flowed down, it led to high-amplitude anomalies being observed in the initial part of the profile (Figure 6B).

The results of the GPR surveys performed along profile GPR-2 were shown in Figure 7A (for $125 \mathrm{MHz}$ antenna) and Figure 7B (for $70 \mathrm{MHz}$ antenna). The effects recorded in radargrams in Figure 7 are quite different from those observed in Figure 6. This was caused by a number of facts (Figure 2), i.e., (a) profile 1 was designed along a geological medium highly changed by anthropogenic activity - profile 2 was designed over natural geological structures, (b) profile 1 was located on soil—profile 2 was located on a road covered 
by asphalt, (c) profile 1 was designed along a slope of the Szyndzielnia mountain—profile 2 was designed perpendicularly to this slope.
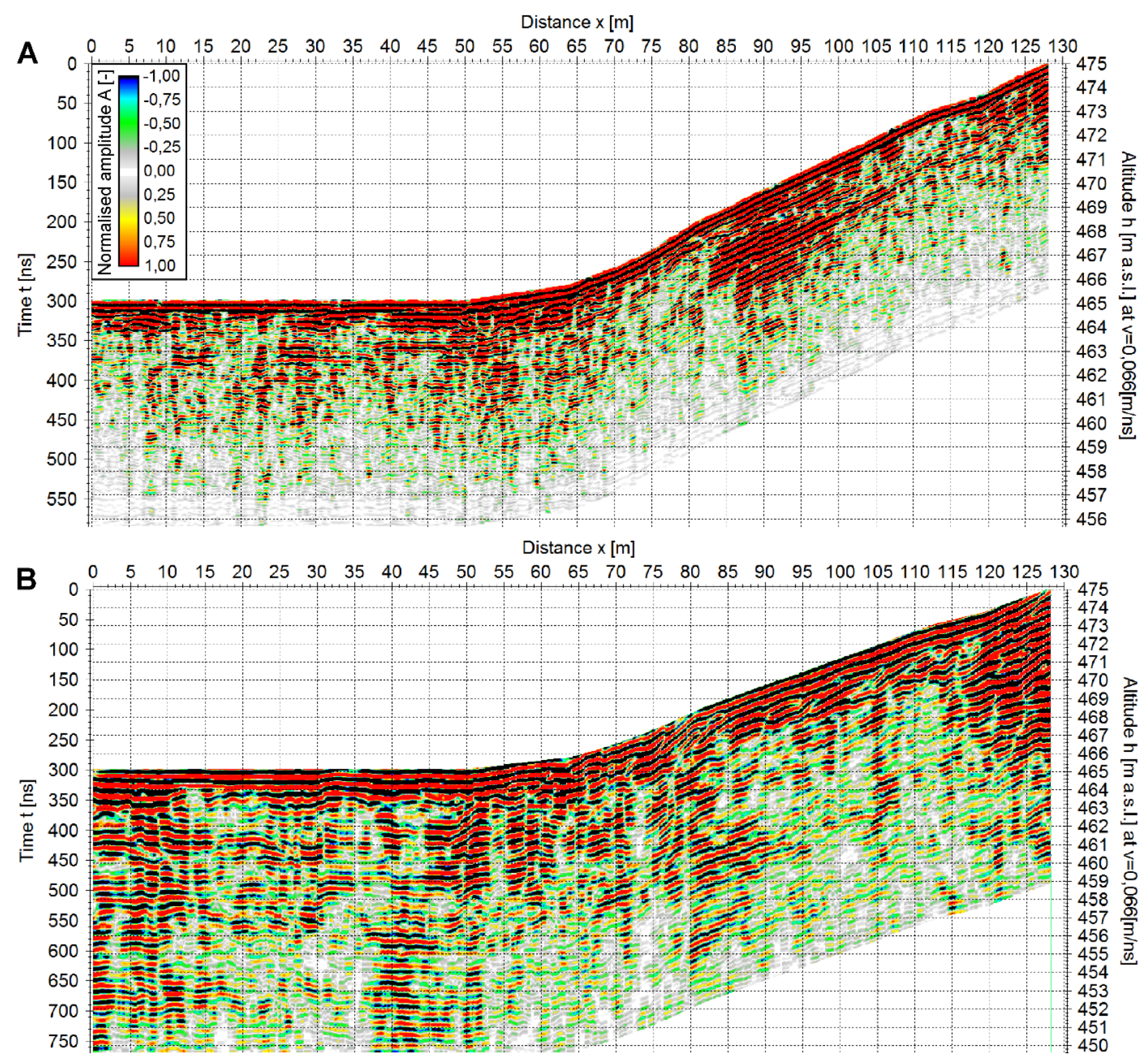

Figure 6. Radargrams recorded along profile GPR-1 with the use of: (A) $125 \mathrm{MHz}$ and (B) $70 \mathrm{MHz}$ antennae.

In Figure 7A, the high-amplitude reflections in the near surface zone (to the depth of $1-2 \mathrm{~m}$ ) change their characteristic at $x=70-75 \mathrm{~m}$. In the first part of the profile, 2 amplitudes are higher and the anomaly reaches deeper which may be caused by different constructions or different disintegrations of the basement of the road before and behind the turn (Figure 2). At greater depths, only one important anomaly may be distinguished, i.e., between $x=50 \mathrm{~m}$ and $x=70 \mathrm{~m}$. It is highly likely that this anomaly depicts the fractured zone which carries the underground water from the Szyndzielnia mountain.

In Figure 7B, the distribution of anomalies at greater depths is different than that of anomalies observed in Figure 7A. Anomalies with very high amplitudes were recorded along the whole profile with a gap between $x=67 \mathrm{~m}$ and $x=93 \mathrm{~m}$. Such distribution of anomalies might, theoretically, depict a large fractured zone filled with water. Such interpretation would be unreliable without additional information from boreholes or results obtained by means of other geophysical methods. Therefore, the GPR surveys along profile 
GPR-2 with the use of $70 \mathrm{MHz}$ antenna were repeated, along the first part of profile from $\mathrm{x}=0 \mathrm{~m}$ to $\mathrm{x}=55 \mathrm{~m}$. Rather than standard (i.e., co-pole) orientation of antennae, measurements were recorded with the application of different antennae orientations (Figure 8).
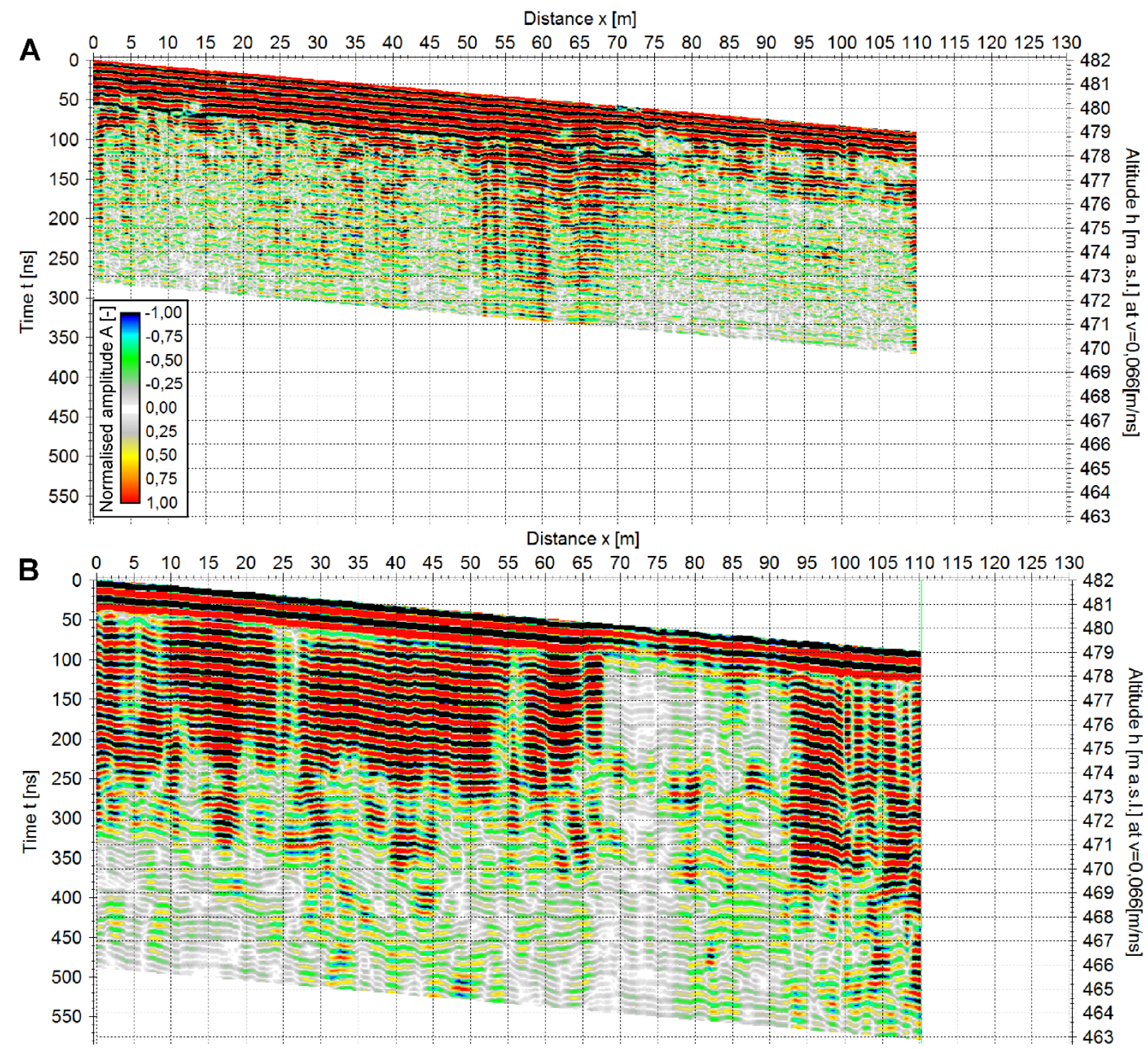

Figure 7. Radargrams recorded along profile GPR-2 with the use of: (A) $125 \mathrm{MHz}$ and (B) $70 \mathrm{MHz}$ antennae.
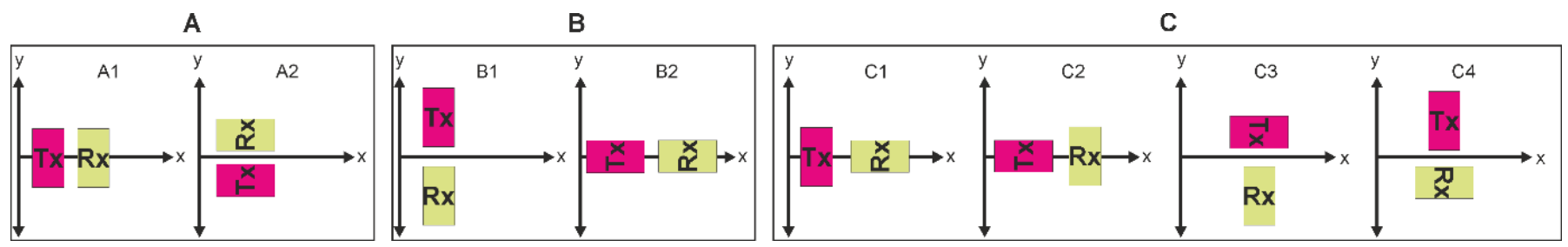

Figure 8. Different orientations of the GPR antennae: (A) "co-pole" orientations; (B) "end-fire" orientations; (C) "cross-pole" orientations.

The majority of the georadar systems that are currently available on the market only permit surveys using a standard orientation of antennae (Figure 8A-option A1) and, consequently, one polarisation of electromagnetic (EM) wave. This is caused by putting both antennae in a bistatic system into one shielded hosting. In the VIY georadar, only one $70 \mathrm{MHz}$ antenna is mounted in separated, shielded boxes so these antennae enable surveys 
to be conducted with different antennae orientations (Figure 8). Due to the limitations of this paper, the theoretical description of the of EM waves propagation with different polarizations in geological media was omitted. Readers interested in this problem may find adequate information in geophysical literature [22-25].

In Figure 9A, in the same zone, several anomalous subzones are discernible; there may be divided into 6 subzones, i.e.,:

- $\quad$ subzones I and II—anomalies with low energies—navy blue colour and light blue colour-these subzones will be correlated with unfractured sandstone, but the navy blue colour (I) refers to homogenous sandstone and the light blue colour (II) refers to sandstone with some heterogeneities;

- $\quad$ subzones III and IV—anomalies with average energies-yellow colour and green colour-these subzones will be correlated with presence of dry fractures (fractures filled with air) in sandstone, but the yellow colour (III) refers to a lower level of fracturing and the green colour (IV) refers to a higher level of fracturing;

- $\quad$ subzones V and VI—anomalies with high energies—red colour and violet colourthese subzones will be correlated with the presence of wet fractures (fractures filled with water) in sandstone, but the red colour (V) refers to a lower level of water saturation in fractures and the violet colour (VI) refers to a higher level of water saturation in fractures.

In Figure 9A, fractured zones are identified along the whole profile to the depth of approximately $8 \mathrm{~m}$; these zones were created by weathering processes. Unfortunately, the GPR method did not deliver information for several meters. Two main underground water channels are located between $x=14-19 \mathrm{~m}$ and $\mathrm{z}=2-8 \mathrm{~m}$ and between $\mathrm{x}=49-53 \mathrm{~m}$ and $z=2-6 \mathrm{~m}$. Other smaller water channels are distributed between $x=27-49 \mathrm{~m}$ and $\mathrm{z}=2-6 \mathrm{~m}$.

In Figure 9B, only a part of the aforementioned underground water channels was confirmed. Such configuration of antennae located the main water channels between $x=24-38 \mathrm{~m}$ and $\mathrm{z}=2-5 \mathrm{~m}$ and between $\mathrm{x}=51-53 \mathrm{~m}$ and $\mathrm{z}=1-7 \mathrm{~m}$. An interesting observation is an appearance of linear anomalies at greater depths-these anomalies may depict the interbedings of shale in sandstone or the horizontal dividing of blocks.

In Figure 9C, two main water channels may be distinguished between $x=4-7 \mathrm{~m}$ and $z=1-6 m$ and between $x=12-16 m$ and $z=1-6 m$; other smaller water channels are distributed between $x=34-49 \mathrm{~m}$ and $\mathrm{z}=1-3 \mathrm{~m}$. At greater depths, linear anomalies, which appear in Figure 9B, are more pronounced and their interpretation is presented above.

In Figure 9D, the main water channels are located between $x=28-36 \mathrm{~m}$ and $\mathrm{z}=1-3 \mathrm{~m}$ and between $x=44-55 \mathrm{~m}$ and $\mathrm{z}=1-5 \mathrm{~m}$. Linear anomalies also appear but they are not as clear as in Figure 9C.

In Figure 9E, the highest number of anomalies appeared which indicated the presence of a dozen or so small water channels located along the whole profile, to the depth of approximately $8-10 \mathrm{~m}$. Linear anomalies are only partly visible in this radargram.

In Figure 9F, a few underground water channels may be distinguish in the near surface zone, to the depth of approximately $6 \mathrm{~m}$. Linear anomalies almost disappear in this radargram.

A general conclusion which may be drawn on the basis of the analysis of the radargrams presented in Figure 9 is as follows: (a) standard co-pole orientation of antennae delivers only general information even after the application of advanced processing, (b) the majority of anomalies were distinguished using a cross-pole polarisation of antennae, (c) the most valuable information from greater depths delivered end-fire polarization [26]. 
Distance $\mathrm{x}[\mathrm{m}]$

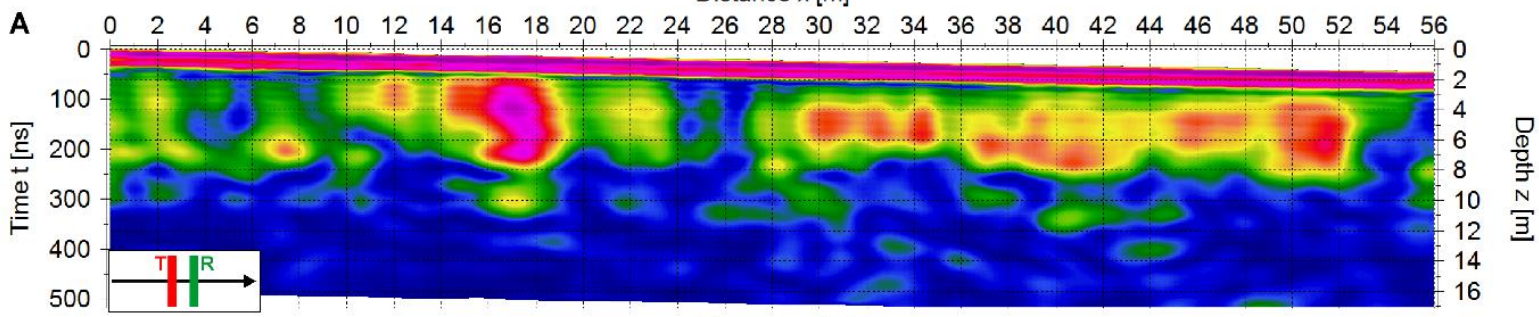

Distance $x$ [m]

B $\quad$\begin{tabular}{lllllllllllllllllllllllllllll}
0 & 2 & 4 & 6 & 8 & 10 & 12 & 14 & 16 & 18 & 20 & 22 & 24 & 26 & 28 & 30 & 32 & 34 & 36 & 38 & 40 & 42 & 44 & 46 & 48 & 50 & 52 & 54 & 56 \\
\hline
\end{tabular}

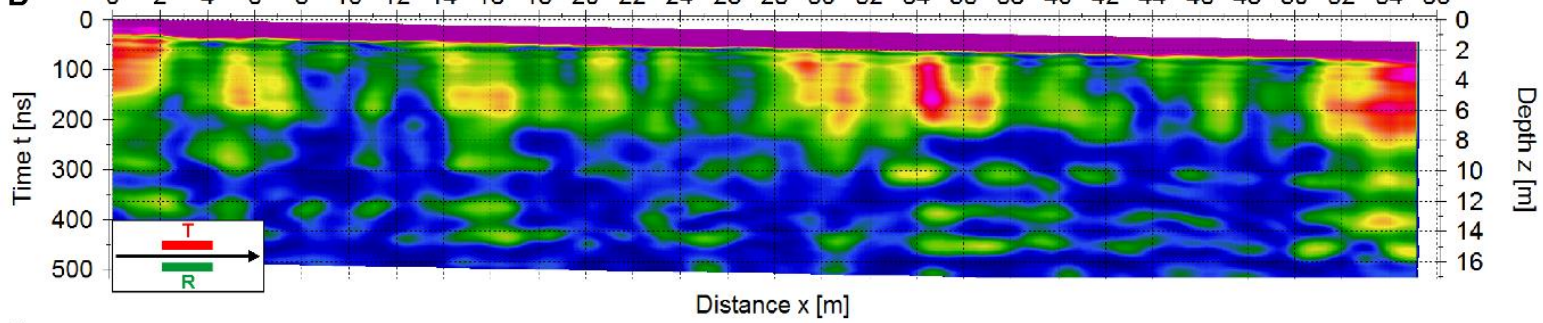

C $\quad$\begin{tabular}{lllllllllllllllllllllllllllll}
0 & 2 & 4 & 6 & 8 & 10 & 12 & 14 & 16 & 18 & 20 & 22 & 24 & 26 & 28 & 30 & 32 & 34 & 36 & 38 & 40 & 42 & 44 & 46 & 48 & 50 & 52 & 54 & 56 \\
\hline
\end{tabular}

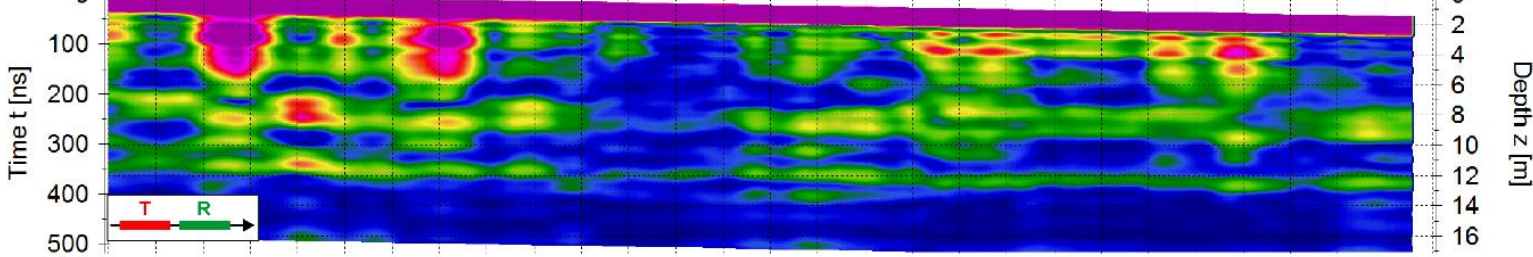

Distance $\mathrm{x}[\mathrm{m}]$

D $\quad \begin{array}{lllllllllllllllllllllllllllll}0 & 2 & 4 & 6 & 8 & 10 & 12 & 14 & 16 & 18 & 20 & 22 & 24 & 26 & 28 & 30 & 32 & 34 & 36 & 38 & 40 & 42 & 44 & 46 & 48 & 50 & 52 & 54 & 56\end{array}$

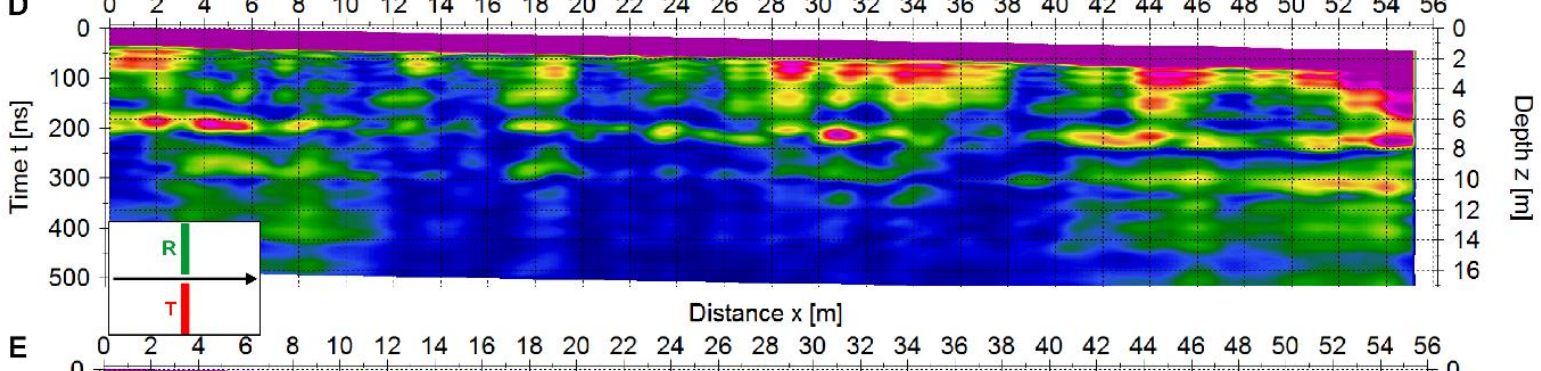

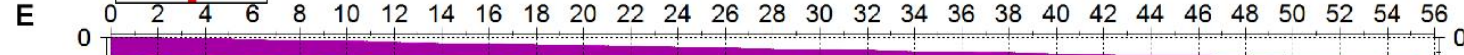

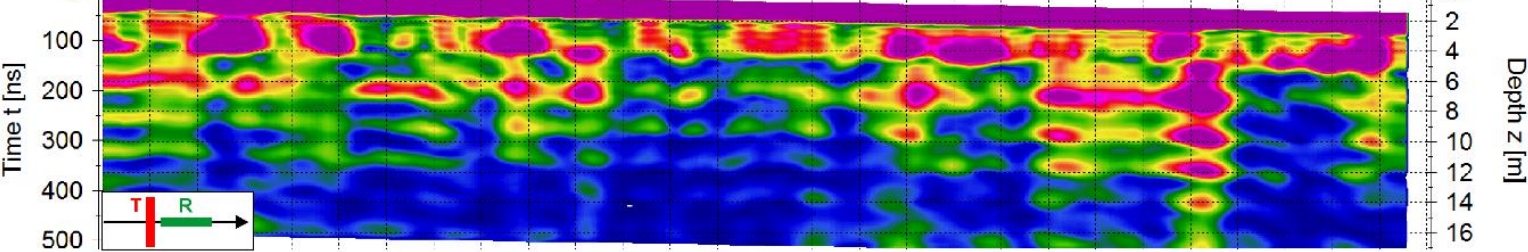

Distance $\mathrm{x}[\mathrm{m}]$

F $\quad \begin{array}{lllllllllllllllllllllllllllll}0 & 2 & 4 & 6 & 8 & 10 & 12 & 14 & 16 & 18 & 20 & 22 & 24 & 26 & 28 & 30 & 32 & 34 & 36 & 38 & 40 & 42 & 44 & 46 & 48 & 50 & 52 & 54 & 56 \\ 0 & & & & & & & \end{array}$

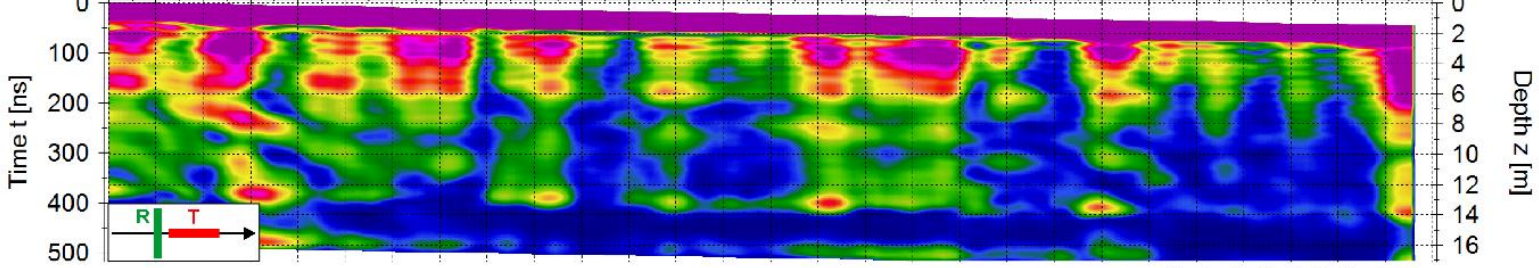

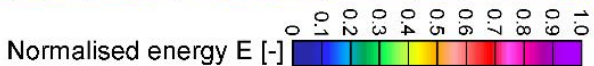

Figure 9. Results of surveys carried out using $70 \mathrm{MHz}$ antenna with different orientations of antennae, see Figure 8: (A) "co-pole" orientation, option A1; (B) "co-pole" orientation, option A2; (C) "end-fire" orientation, option B2; (D) "endfire" orientation, option B1; (E) "cross-pole" orientation, option C1; (F) "cross-pole" orientation, option C2. 


\subsection{ERT Surveys}

An ERT survey was carried out along the profile lines 1 and 2 (Figure 2). The total length of the profile lines were $128 \mathrm{~m}$ and $110 \mathrm{~m}$, respectively.

The ERT surveys were made with the basic electrode spacing $\Delta x=2 \mathrm{~m}$, where lengths of current and potential dipoles were $\mathrm{a}=1,2,5,9,14 \Delta \mathrm{x}$ and a separation factor $\mathrm{n}$, which is the ratio of the distance between the current and potential dipole, equals $n=1,2,3,4,5$. These parameters resulted in a proper depth and resolution for the necessary investigations [27]. The dipole-dipole array was used to obtain the best horizontal resolution [28-32]. The ERT survey was carried out using Ares II resistivity meter [33].

The obtained apparent resistivity datasets were inverted using the Res2dinv of Geotomo Software [34]. In order to reduce the influence of the terrain's morphology on the measurements, the collected terrain morphology data was used during the inversion process [34-39]. During the inversion process, two methods, L1-norm (robust and blocky) and L2-norm (smooth), were tested. The first method typically produces geoelectrical models with much sharper boundaries between resistivity zones and the second one normally yields more blurry boundaries [29]. In the following case, the robust inversion method [34] was applied to the field data, which provided a lower value of the root mean square error (RMS) than the L-2 norm inversion method.

The field data inversion results were shown as a $2 \mathrm{D}$ resistivity cross-section in Figures 10 and 11. Information gathered from piezometers about the water table level was also superposed on the figures.

The field data was inverted with using Res2dinv software [29,30]. A robust inversion [34] was applied to the field data. The inversion results are shown in leakage zone no. I-II and the CCR cross-section (which is discussed in Section 3.3) were also superimposed.

In the resistivity cross-sections, the relatively low anomalies ("L1" to "L5") and high resistivity anomalies from " $\mathrm{H0}$ " to " $\mathrm{H} 3$ " are distinguishable.

The high resistivity anomalies are in blocky form and were spotted for $\mathrm{x}=22-33$, $40-58,89-110 \mathrm{~m}$ of the profile line. The anomalies are characterized by resistivity values equal to approximately $10,000 \Omega \mathrm{m}$. It is worth noting that the "H0" anomaly, located between the $\mathrm{H} 2$ and $\mathrm{H} 3$ anomalies, has a very similar shape to the other " $\mathrm{H}$ " anomalies but the resistivity value equals approximately $250 \Omega \mathrm{m}$.

The low resistivity anomalies, "L1"-_L4" and "L6", are located in the shallowest parts of the studied area with one exception, where anomaly "L5" is approximately $10 \mathrm{~m}$ below the ground surface. The anomalies' resistivity value is within a range between $60-150 \Omega \mathrm{m}$.

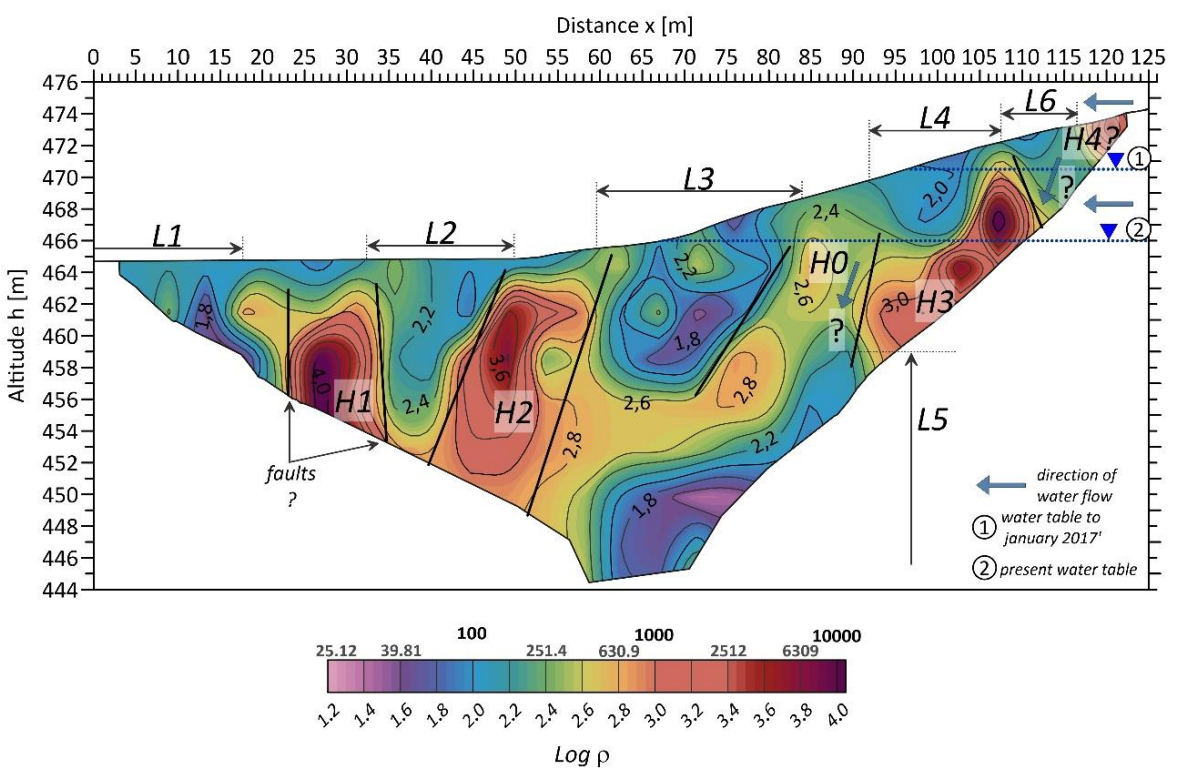

Figure 10. Inverted resistivity cross-section for profile $1 ; \mathrm{RMS}=6.37 \%$. 
From a geological point of view, the low resistivity anomalies "L1" to "L4" may be interpreted as clay partly mixed with sands, which suggests the resistivity value is approximately 1.6 times greater than that of typical pure clays. It is worth noting, that the low resistivity anomalies are not completely homogeneous, which is especially visible for the "L1" and "L3"zones. In the above-mentioned areas, the presence of pure clay with a very low value of water permeability is noticeable. The "L5" anomaly should be interpreted as highly fractured and saturated sandstone.

The high resistivity anomalies " $\mathrm{H} 1$ ", " $\mathrm{H} 2$ " and "H3" anomalies would appear to be sandstone.

In summary, the first geological layer consists of clay mixed with sands. The layer's thickness is variable and, with the exception of the " $\mathrm{L}$ " anomalies, is equal to approximately $4 \mathrm{~m}$ for $\mathrm{x}=0-50 \mathrm{~m}$ and for $51-120 \mathrm{~m}$ is approximately two times smaller. The second layer (sandstone), does not continue and occurs in blocky form. The thickness of the sandstone is approximately $12 \mathrm{~m}$. Gaps between the sandstone blocks are filled with the material from the first layer. A discontinuity in the sandstone layer may be caused by an erosion/suffusion process related to the water flow from the Szyndzielnia mountain or the presence of tectonic forms like faults (cf. Figure 10). It is also highly probable that in the first step, the sandstone layer was broken by the faults, which consequently intensified the erosion process. Proof that the erosion/suffusion process (mainly water influence) is very active nowadays is the "H0" anomaly, which has a blocky form (like sandstone) but the resistivity value is approximately 40 times lower than the other sandstone cases.

As for the water flow in the studied area, it is worth noting that information from piezometers indicates a decreasing water table level. This is probably connected with the fault at $x=90 \mathrm{~m}$, where the developing erosion process found a way for the underground water flow along the fault plane. Thereupon, the fracture sandstone ("L5") can be filled by water. In general, the area from $x=80 \mathrm{~m}$ to $\mathrm{x}=118 \mathrm{~m}$ of the profile line is mainly responsible for the underground water flow. It is also probable that the water is in the subsurface area in the "L2", "L3" and "L3" clays.

In the next stage, the resistivity cross-section for profile 2 was analyzed (Figure 11).

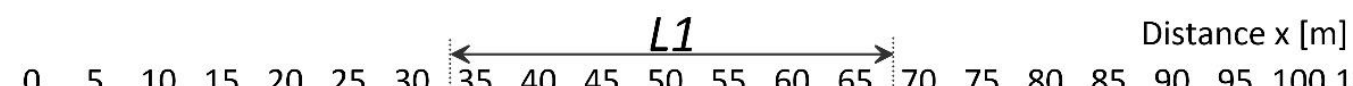

$\begin{array}{lllllllllllllllllllllll}0 & 5 & 10 & 15 & 20 & 25 & 30 & 35 & 40 & 45 & 50 & 55 & 60 & 65 & 70 & 75 & 80 & 85 & 90 & 95 & 100 & 105 & 110\end{array}$
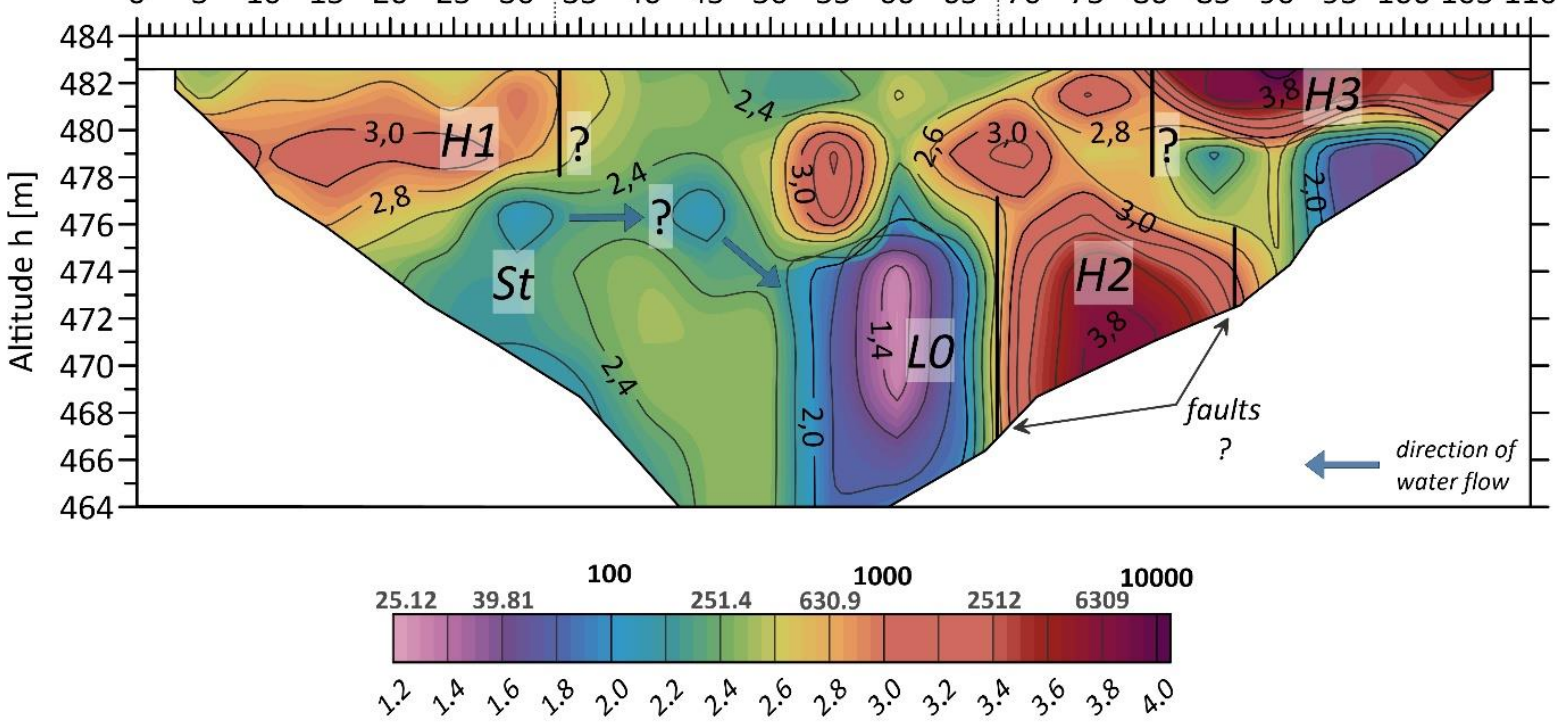

$\log \rho$

Figure 11. Inverted resistivity cross-section for profile $2 ; \mathrm{RMS}=14.69 \%$.

Similarly to profile 1, the relatively low ("L0", "L1") and high ("H1" to "H3") resistivity anomalies are distinguishable. 
The low resistivity anomalies are concentrated mainly in the profile canter $(x=33 \mathrm{~m}-68 \mathrm{~m})$ and continue throughout the whole profile's depth. The anomalies are characterized by the resistivity ranging from $25 \Omega \mathrm{m}$ to $250 \Omega \mathrm{m}$.

The high resistivity anomalies " $\mathrm{H} 1$ " and "H3" have a blocky form and appear between $\mathrm{x}=0-33 \mathrm{~m}$ and $\mathrm{x}=80 \mathrm{~m}$ to the end profile in the subsurface zone. The anomaly " $\mathrm{H} 2$ " lies approximately $7 \mathrm{~m}$ below the ground surface. The resistivity range equals between $600 \Omega \mathrm{m}$ and $6000 \Omega \mathrm{m}$.

From a geological point of view, the high resistivity anomalies should be interpreted as sandstone blocks. It would appear that the "H3" block is faulted. Faulting in case of "H1" and "H3" sandstones is less probable. The "L" anomaly, in turn, is probably a highly fractured sandstone.

Likewise in profile 1, zones most likely to be filled with water were picked. It is highly probable that fractured sandstone from the "L1" zone is characterized by a relatively high water permeability and consists of a way for the water to flow from the Szyndzielnia Pick. It is worth noting that approximately $6 \mathrm{~m}$ below the ground surface the structural anomaly "St", which is probably a form of underground channel where water has a relatively easy path to flow. This conclusion seems probable because at the "St" structure's end, the very low anomaly "L0" is spotted, which is related to water saturation.

\subsection{CCR Surveys}

Over the past few years, in the field of shallow geophysical investigations, the capacitively-coupled resistivity method (also referred to as the CCR method) has been one of the fast-growing geophysical research techniques [40,41].

CCR, like ERT methods, allows for an estimate of the ground's apparent resistivity value but the main difference is in the acquisition process, where the measurement is realised using cumbersome galvanic electrodes, which are pulled along on the ground by a small vehicle or by a single person. The measurement can be carried out in $2 \mathrm{D}$ or 3D geometry and provides readings from a geological medium up to a few meters $[42,43]$.

The most important advantage of this method is the possibility to collect data quickly in an almost continuous way, which is indirectly connected with the lack of requirement to apply metal sticks into or on the ground. Furthermore, the horizontal resolution in the method is high and it is increased when the measurement is performed at a smaller velocity, for example by a single person.

One weakness of this method is the user is limited to only one measurement array, the dipole-dipole array, which is sensitive to noise [44-46].

The CCR measurements were carried out in the continuous mode. The OhmMapper geometry was set up using three receivers $(\mathrm{R} \times 1-\mathrm{R} \times 3)$ and a standard single transmitter $\mathrm{Tx}$. The applied settings are shown in Figure 12 below.

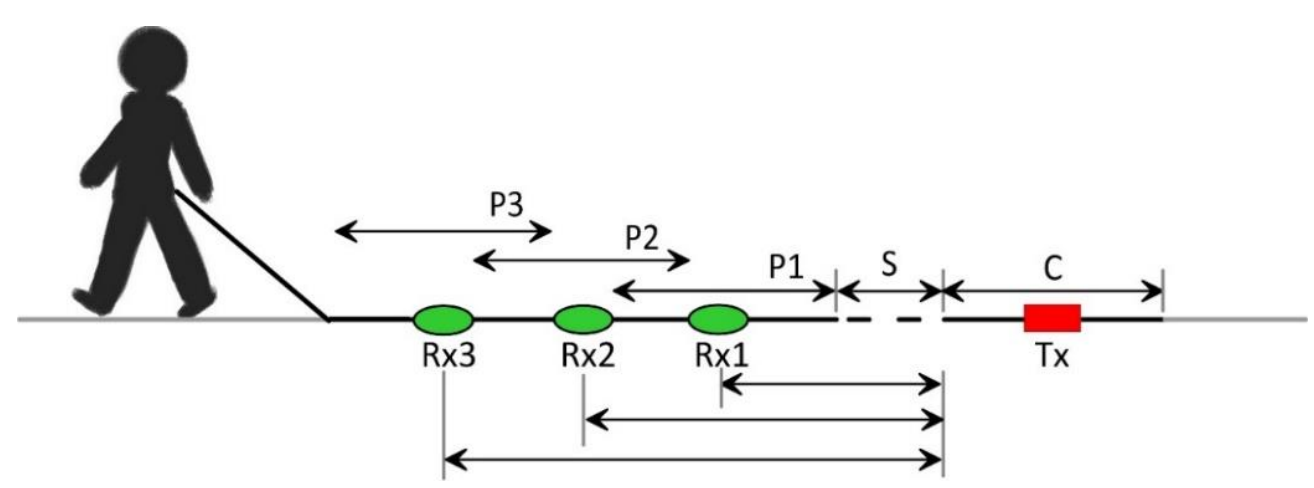

Figure 12. Schema of the OhmMapper with 3 receivers $(\mathrm{Rx})$ and transmitter (Tx) being pulled by a single person; the potential dipoles (P1-P3), the current dipole (C), the separation (S).

The detailed geometry of the OhmMapper array was shown below in Table 1. 
Table 1. Geometry of the OhmMapper applied during the measurements.

\begin{tabular}{ccccccc}
\hline $\begin{array}{c}\text { Measuring } \\
\text { Series }\end{array}$ & $\begin{array}{c}\mathbf{R x 3} \\
\mathbf{( m )}\end{array}$ & $\begin{array}{c}\mathbf{R x 2} \\
\mathbf{( m )}\end{array}$ & $\begin{array}{c}\mathbf{R x 1} \\
\mathbf{( m )}\end{array}$ & $\begin{array}{c}\mathbf{S} \\
\mathbf{( m )}\end{array}$ & $\begin{array}{c}\mathbf{T x} \\
\mathbf{( m )}\end{array}$ & $\begin{array}{c}\text { Receivers } \\
\text { Number }\end{array}$ \\
\hline 1 & - & - & 5 & 5 & 5 & 1 \\
2 & - & - & 5 & 10 & 5 & 1 \\
3 & - & - & 5 & 15 & 5 & 1 \\
4 & - & - & 10 & 10 & 10 & 1 \\
5 & - & - & 10 & 15 & 10 & 1 \\
6 & - & 7.5 & 5 & 5 & 5 & 2 \\
7 & - & 7.5 & 5 & 10 & 5 & 2 \\
8 & - & 7.5 & 5 & 15 & 5 & 2 \\
9 & 10 & 7.5 & 5 & 5 & 5 & 3 \\
10 & 10 & 7.5 & 5 & 10 & 5 & 3 \\
\hline
\end{tabular}

In the next stage, the obtained field data was analysed using OhmImager (Data analysis applet). In the software, the following steps were applied: firstly, the data was examined, then the accuracy of the geometry was checked and, in some cases, adjusted. Secondly, the erroneous data was removed in two ways by deleting the individual pieces of data and by using a median filter [47].

Finally, the CCR data was exported in a format compatible with Res2dInv software, where the inversion process was performed. All of the inversion parameters were identical to those in the ERT data case.

In order to enable a comparison of the CCR and ERT data, both cross-sections were shown (Figure 13). Additionally, the ERT depth investigation was limited to $5 \mathrm{~m}$ below the ground surface, which is the CCR maximum depth of the investigation. It is worth noting that the measurements were not carried out at the same time. The CCR measurements were performed on 15th October and the ERT measurements on 5th November 2020.

Similar to the previous case, the relatively high resistivity anomalies ("H1" to "H4") and the low resistivity anomalies, which are interpreted sequentially as sandstones and mixture of sands and clays, were detected.

In general, the considered resistivity sections are quite similar up to roughly the 80th meter of the profile line. In the rest of the profile, some changes are observed. First of all, the "L3" anomaly (clays and sands) in the CCR cross-section has a higher resistivity value and a smaller size than in the ERT profile. Secondly, significant changes are observed in sandstone " $\mathrm{H0}$ ". The aforementioned sandstone block is interrupted by a low resistivity anomaly which narrows with increasing depth. Finally, sandstone "H3" was not detected in the CCR cross-section.

In terms of identifying where the presence of faults may be in the CCR cross-section, it is not possible to recognize a fault for $x=80 \mathrm{~m}$ and $\mathrm{x}=110 \mathrm{~m}$ of the profile line. These measurements also revealed faults for $\mathrm{x}=120 \mathrm{~m}$.

These changes in the resistivity distribution can be partly explained by the fact that the CCR and ERT methods reflect resistivity distribution in slightly different ways, yet it seems more probable that the changes in the resistivity distribution are caused by a very active water flow, especially from $x=60$ to $x=120 \mathrm{~m}$ of the profile length. The above observations prove that the discussed area is fractured and the water flow is dynamic over time. 

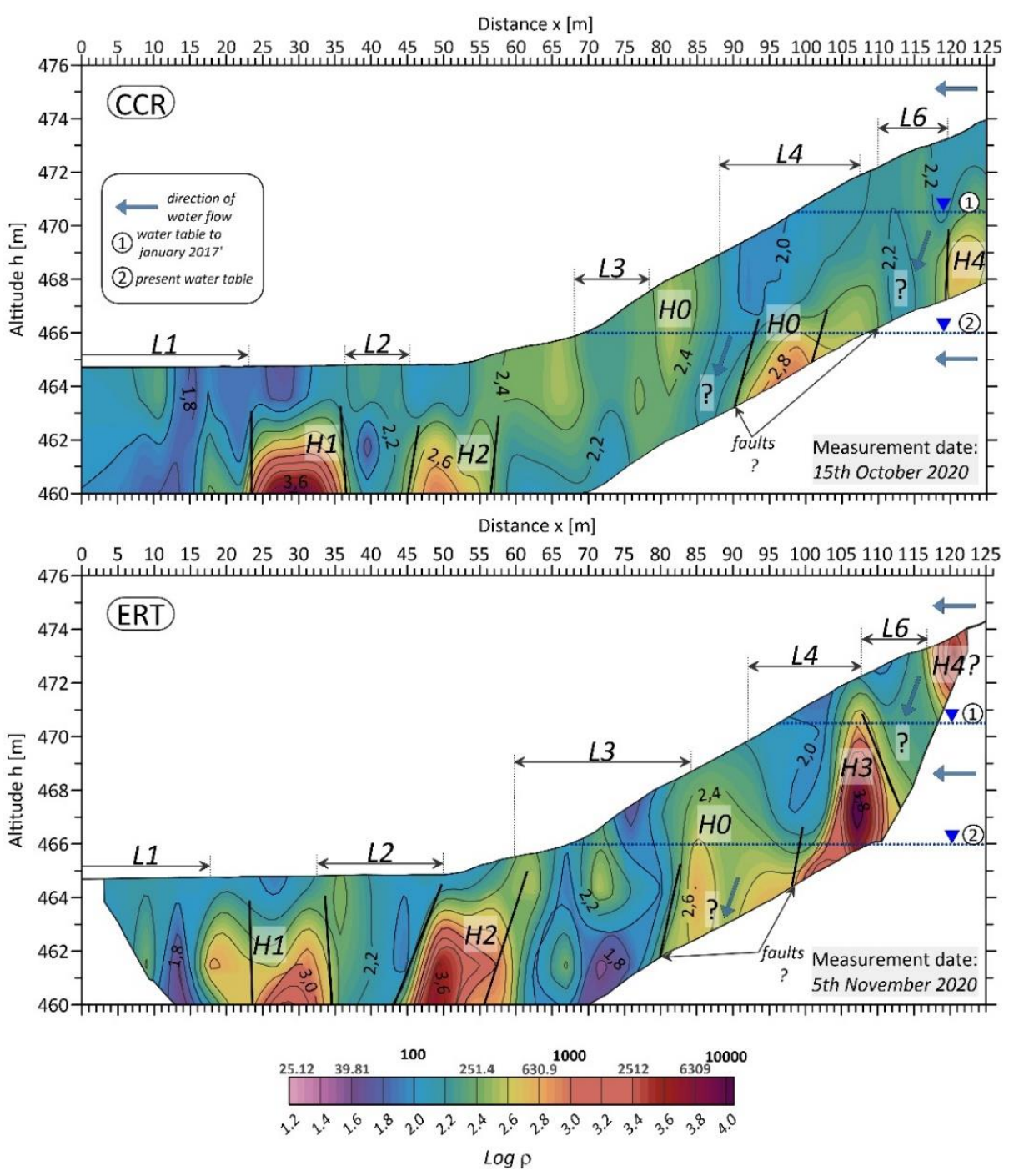

Figure 13. Inverted resistivity cross-section for the CCR method (above) and ERT method (below); RMS $=11.36 \%(C C R)$ and $6.37 \%(E R T)$.

\subsection{Seismic Surveys}

High resolution seismic reflection surveys were carried out as supplementary measurements for the GPR, ERT and CCR surveys. The GPR techniques delivered information about the geological medium to a maximum depth of $16 \mathrm{~m}$, but the main anomalies were detected between the surface and a depth of approximately $10 \mathrm{~m}$. The ERT and CCR techniques allowed for the detection of anomalies to a maximum depth of $8 \mathrm{~m}$. In such situations, seismic surveys should deliver data from depths greater than $10 \mathrm{~m}$. As described in the introduction, the geological investigations revealed in greater depths the presence of sandstones and mudstone shale formations. Additionally, in the subsoil of the dam, faults and highly fractured rocks occurred. Therefore, the goal of seismic surveys was the detection of the main geological layers and the identification of the faults.

For the seismic surveys, two measurement methods were applied, i.e.,: (a) the High Resolution Reflection Seismic (HRRS) method which is the method of choice for this study and (b) a new method proposed by the authors, i.e., using surface waves (SW). The SW technique should not be confused with MASW as it is based on the study of the local attenuation of surface waves by geological heterogeneity, especially that of faults.

The particularity and difficulty of the HRRS method (in comparison with the "classic" deep seismic methodology) lies in the fact that the signals reflected from shallow targets are generally mixed with a background of coherent noise $(\mathrm{CN})$, i.e., surface waves, ground-roll, 
refractions and air coupled waves. Therefore, the primary way to discover the researched shallow reflections is to find the so-called Optimum Offset Window (OOW), that is, the offset interval where the reflection/CN is most favorable. In addition, it is necessary to dispose the data of sufficiently high frequency in order to distinguish the shallow reflections in the background of the CN. During the acquisition, the closest offset was kept constant (the source and receivers were rolled by the receiver spacing) in order to maintain a constant value of the OOW.

It should be pointed out that the decrease of the depth of interest does not facilitate the work to be done, as could be expected. That is why the progress of the HRSR method is measured by the decrease of the shallowest prospected depth. In this context, the targeted depth of boundary " $\mathrm{A}$ " close to $4-5 \mathrm{~m}$ is quite small and such case is referred to as Very High Resolution Reflection Seismic (VHRRS) [48,49].

In terms of the pulse-echo imaging device, a seismic CDP (Common Depth Point) gather is equivalent to the sounding with the synthetic aperture array of dimension $\mathrm{D}$ (close to the OOW's length) focused, by using a normal move out, at the subsurface point known as the CDP at depth $d$ [22]. The results of processing are equivalent to sounding with a point probe, moving along the profile, focused at a given CDP. The set of traces presented as a function of the CDP position gives the final output image (Figure 14). The image lateral resolution is assumed to be equal to the Fresnel radius $(\lambda d / 2) 0.5$, where $\lambda$ a is the apparent processed acoustic wavelength, defined as: $\Delta \mathrm{a}=\mathrm{Vrms} / \mathrm{fd}$ (where Vrms is the stacking velocity, fd is the dominant signal frequency and $d$ indicates the depth). The depth resolution $\delta \mathrm{r}$ within the first detected layer may be estimated as equal to $1 / 4 \lambda$ a. Finally, achieving appropriate depth and lateral resolutions requires the use of short wavelengths i.e., high frequencies [50]. Since ground absorption increases with frequency, the highest exploitable frequency is always limited and mostly depends of the source used.

In the presented study, the optimal solution was to use a wide-banded explosive type of Betsy gun or a shotgun but the use of such source was prohibited on site because of its destructive nature. Finally, a sledgehammer (one blow, no stacking) was used as the source.

The HRRS profile was conducted along the line indicated in Figure 2, but it was shortened to $110 \mathrm{~m}$ in compression with the GPR profile $(128 \mathrm{~m})$. The acquisition was carried out using a 48-channel Geometrics Strata Visor NZXP seismograph. End-off geometry was applied in order to get better velocity estimation.

Acquisition was carried out using $26-\mathrm{Hz}$ geophones in order to reach a compromise between the primary low-cut suppression of the ground-roll [50] and the greatest depth possible (this requires smaller frequencies since the ground absorption increases with frequency). The nearest offset, chosen with respect to the depths of the researched boundary " $\mathrm{A}$ ", was set to $1 \mathrm{~m}$. According to the principles used for the research of anomalies [51], the geophone spacing was set to $1 \mathrm{~m}$, yielding a CDP resolution of $0.5 \mathrm{~m}$. The profile was processed using Winses18 software [52] and applying the HRRS CDP processing flow, namely: input band pass filtering, first arrival and air-coupled wave muting, FK filtering, scaling, optimum offset window apply (offset windowing), velocity analysis, $\mathrm{NMO}$ correction, CDP stacking, post-stack band pass filtering. The acquisition geometry and obtained resolutions in layer I are summarized in Table 2.

Table 2. Geometry and basic resolutions of two HRS profiles.

\begin{tabular}{|c|c|c|c|c|c|c|c|c|c|}
\hline Geophones & Source & $\begin{array}{l}\text { Number of } \\
\text { Shots }\end{array}$ & $\begin{array}{c}\text { Minimum } \\
\text { Source } \\
\text { Receive Offset }\end{array}$ & $\begin{array}{l}\text { Geophone } \\
\text { Spacing }\end{array}$ & $\begin{array}{c}\text { CDP } \\
\text { Spacing }\end{array}$ & $\begin{array}{l}\text { Achieved } \\
\text { Dominating } \\
\text { Frequency } \\
\text { in Stacked } \\
\text { Section } \\
\text { fd }\end{array}$ & $\begin{array}{c}\text { Dominating } \\
\text { Wavelength } \\
\text { in the First } \\
\text { Layer } \\
\lambda d\end{array}$ & $\begin{array}{c}\text { Depth } \\
\text { Resolution } \\
\text { in the First } \\
\text { Layer } \\
\delta r\end{array}$ & $\begin{array}{c}\text { Lateral } \\
\text { Resolution } \\
\text { at Depth of } \\
\text { Boundary "A" } \\
\delta x\end{array}$ \\
\hline $26 \mathrm{~Hz}$ & $\begin{array}{c}\text { Sledge } \\
\text { hammer } \\
5 \mathrm{~kg}\end{array}$ & 126 & $1 \mathrm{~m}$ & $1 \mathrm{~m}$ & $0.5 \mathrm{~m}$ & $100 \mathrm{~Hz}$ & $3 \mathrm{~m}$ & $\begin{array}{l}\text { from } 0.75 \mathrm{~m} \\
\quad \text { to } 1.5 \mathrm{~m}\end{array}$ & $2.4 \mathrm{~m}$ \\
\hline
\end{tabular}


The obtained seismic sections and its interpretation are shown in Figure 14. During signal processing it was found that the OOW for boundary " $\mathrm{A}$ " fits the offset interval between $3 \mathrm{~m}$ and $8 \mathrm{~m}$, however for the subsequent boundaries, the OOW starts from $15 \mathrm{~m}$. Therefore, the results are presented on two separate sections (Figure 14A,B).

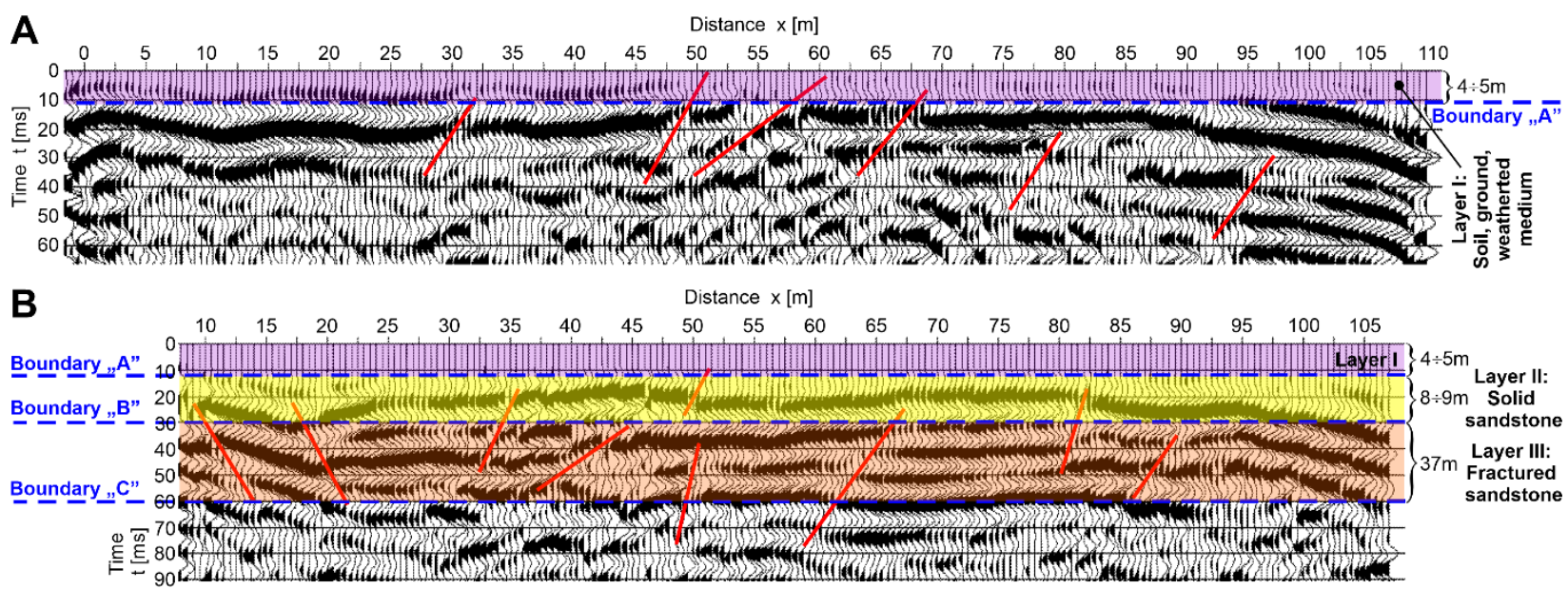

Figure 14. The high resolution seismic reflection profiles obtained along the top of dike and their interpretation. (A) $100 \mathrm{~Hz}$ profile, LRA symbols indicate the Loss of Reflection from A zones, straight black lines indicate shallow faults (B) $26 \mathrm{~Hz}$ profile.

The obtained results indicate the presence of three main layers marked I, II, III and this depth of layer I correlates with the depth previously obtained by the ERT technique (see Figure 10). The obtained interval velocities for layers I, II and III, and their geological interpretation are shown in Table 3 and illustrated in Figure 14 (on the right). These velocities were independently checked by refraction and provide similar results. It can be observed that the event noted as boundary " $\mathrm{C}$ " can constitute multiple reflections of boundary " $\mathrm{B}$ " and, therefore, it may not be considered as a geological boundary. The observed increase of the depth of boundaries " $\mathrm{A}$ ", " $\mathrm{B}$ " and " $\mathrm{C}$ " in the final part of the profile is caused by sloping of the profile (no static correction for this sloping is introduced); in fact the detected boundaries are not sloping.

Table 3. Interval velocities in layers I, II and III obtained from CDP = 302 and from refraction (one arbitrarily chosen shot \#21).

\begin{tabular}{|c|c|c|c|c|c|}
\hline \multirow[b]{2}{*}{ layer } & \multirow[b]{2}{*}{ Material } & \multicolumn{2}{|c|}{$\begin{array}{c}\text { Velocities Obtained from } \\
\text { HRSR }\end{array}$} & \multicolumn{2}{|c|}{$\begin{array}{l}\text { Velocities Obtained from } \\
\text { Refraction from Shot \#21 }\end{array}$} \\
\hline & & Depth & $\begin{array}{c}\text { Interval P } \\
\text { Velocity }\end{array}$ & Depth & Velocity \\
\hline I & sand & $4-5 \mathrm{~m}$ & $\begin{array}{c}700-1000 \\
\mathrm{~m} / \mathrm{s}\end{array}$ & $6 \mathrm{~m}$ & $700 \mathrm{~m} / \mathrm{s}$ \\
\hline II & clay & $13-15 \mathrm{~m}$ & $\begin{array}{c}2000-2200 \\
\mathrm{~m} / \mathrm{s}\end{array}$ & $15 \mathrm{~m}$ & $1700 \mathrm{~m} / \mathrm{s}$ \\
\hline III & $\begin{array}{c}\text { Saturated } \\
\text { ground }\end{array}$ & $>50 \mathrm{~m}$ & $>3000 \mathrm{~m} / \mathrm{s}$ & - & - \\
\hline
\end{tabular}

It is worth noting that the boundaries " $\mathrm{A}$ " and " $\mathrm{B}$ " display numerous discontinuities which can be interpreted as shallow faults. These faults were previously detected by the ERT technique. This suggests that dam leakage (which is in the origin of this study) may be caused by the presence of the faults.

The MASW method [53] includes four stages: acquisition of the seismic signal, extraction of the surface wave (SW), determination of its velocity dispersion and, finally, its inversion. The method proposed in the paper named MASW-a, begins with the same first 
two stages. In the third stage, the instantaneous amplitude $\mathrm{A}(\mathrm{x})$ of the SW is determined as a function of the profile position " $x$ " (directly in the time domain via Hilbert transform). The method is based on the assumption that each fault (or another "obstacle") causes additional local SW attenuation at the fault's position. Thus, the fourth stage consists in determining the local SW attenuation $\alpha_{\text {local }}(\mathrm{x})$ as:

$$
\alpha_{\text {local }}(\mathrm{x})_{\mathrm{db}}=8.63 \ln (\mathrm{A}(\mathrm{x})) / \mathrm{A}(\mathrm{x}+\Delta \mathrm{x})
$$

where: $\alpha_{\text {local }}(\mathrm{x})$ can be interpreted as the modulus of the transfer function between the SW signals recorded at the neighbouring points " $x$ " and " $x+\Delta x^{\prime \prime}$ ( $\Delta x$ indicates the geophone spacing). Therefore, the abnormal increase $a(x)$ may be interpreted as the fault presence symptom. The MASW-a method is developed and successfully used in the detection and tracking of cracks in nuclear plants in France [42,44]. In this study, the method is transposed to the seismic domain in order to perform fault detection along the prospected profile. This is the first test for this novel and original approach in the seismic domain.

The $\alpha_{\text {local }}(x)$ parameter was obtained by using the following processing flow: the band-pass filtering in 30-60 kHz (a bandwidth of the SW), FK filtering in interval of the SW velocities 300-600 m/s, (the SW velocities), the A(x) determination and, finally, the alocal(x) computed by using (equation1). Within this frequency band, the SW penetration (which can be assumed to be an SW wave length), can be estimated at $20 \mathrm{~m}$. The obtained results are presented in Figure 15A,B. Notice that for the rolling of the acquisition channels, the anomalies of the SW associated with a given profile position form a vertical line. This is clearly seen in Figure 15A. In order to improve the alocal(x) reliability, the alocal(x) values obtained from each shot are stacked and the final result is shown in Figure 15B. It follows from this result that the most significant anomalies are located in the regions marked in Figure 15A,B. Both positions of anomalies correlate well with the faults indicated in Figure 14A,B. In general, the obtained results indicate that $\alpha_{\text {local }}(\mathrm{x})$ can help in classifying the faults quantitively and such classification is not possible through a classic seismic section.

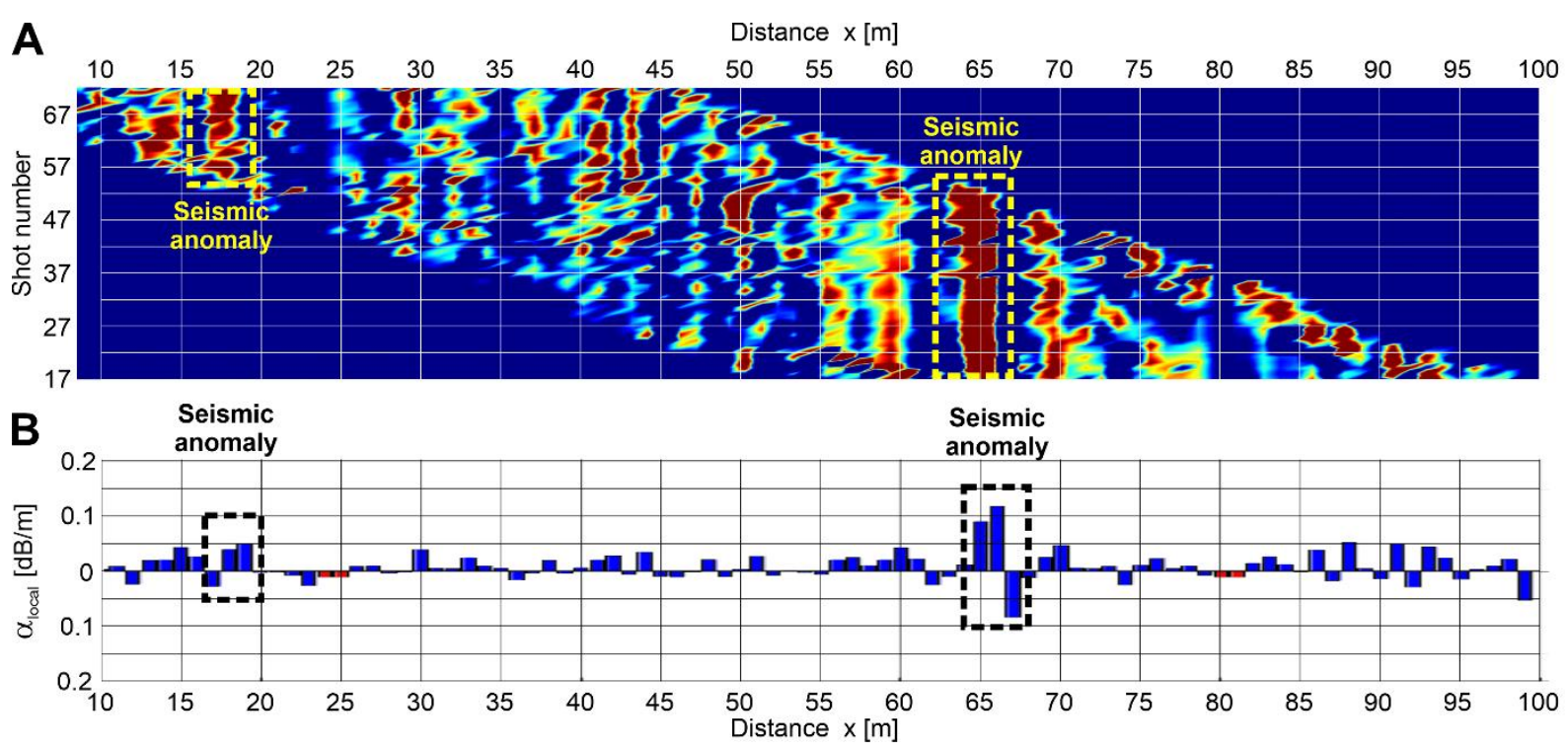

Figure 15. (A) $\alpha_{\text {local }}$ parameter as a function of the number of shots and the profile's position; (B) stacked $\alpha_{\text {local }}$ as a function of profile position.

\section{Complex Interpretation and Discussion}

The studied area is characterized by complex hydrological phenomenon connected with the underground water flow. The mentioned phenomena are on the geological background, which is poorly recognized with the use of the methods applied in the 20's 
and 30's [3,4]. Furthermore, based on this incomplete and simplified information, in order to gather the underground and surface water, the drainage system was designed. The system in theory should provide a greater stability of the construction. Unfortunately, these actions was not effective. Thereupon, to recognize geological structure and point the water paths the geophysical measurements were carried out. The scope of study is very local because the mentioned early problem is focused in the SE part of the dam.

In turn of the geophysical point of view The first layer is characterized by a resistivity value from $60 \Omega \mathrm{m}$ to $150 \Omega \mathrm{m}$ and a velocity ranging between $700 \mathrm{~m} / \mathrm{s}$ and $1000 \mathrm{~m} / \mathrm{s}$. The layer thickness is diversified and It equals $4 \mathrm{~m}$ for $\mathrm{x}=0-50 \mathrm{~m}$ and $2 \mathrm{~m}$ for the rest of the profile, which is confirmed by all applied methods.

From a geological point of view, the first layer cannot be interpreted as clear clay, which suggests the raised resistivity value obtained from the CCR and ERT methods. In the case, where the presence of the weathered diluvial sediments will be taken in consideration, the raised resistivity value is explainable. Additionally, the GPR method shows that highamplitude anomalies are present in the layer, which indicates that the medium is porous and it can be filled by water from precipitation and/or melted snow. The early presumption is confirmed by the results of the seismic interpretation, where the decrease of the velocity is spotted.

The second layer is characterized by a resistivity value of up to approximately $10,000 \Omega \mathrm{m}$ and a velocity of approximately $2000 \mathrm{~m} / \mathrm{s}$. Based on the high resistivity and velocity and the available geological information, the second layer should be interpreted as a fractured sandstone. Both methods indicate that the layer has a thickness of approximately $12 \mathrm{~m}$. Additionally, the ERT method proves that the layer is not continuous and has a rather blocky form. The gaps between the sandstone blocks are filled with the first layer material. Based on the ERT results, it is possible to say that the blocky forms of sandstones are caused by faults. This assumption was confirmed by the seismic results. In the matter of the presence of the layers of shales, there is no indication that the layer is present, which is connected with the fact that the mentioned layer is probably too thin to be detected by any of the applied geophysical methods.

Within the second layer, a sublayer draws attention is characterized by a resistivity of up to $150 \Omega \mathrm{m}$ and a velocity of approximately $3000 \mathrm{~m} / \mathrm{s}$. Based on the ERT interpretation, it cannot be said that the layer is definitely dry and fractured sandstone from a geological point of view. Unless, it will be assumed that the layer is extremely fractured and filled with water. Based on information from the drillings the mentioned layers is yellow and yellow-grey fractured sandstone.

In order to indicate the areas of water presence/flows, the interpreted results of the electrical and electromagnetics methods (ERT, CCR, GPR) were chosen. The selected methods are sensitive to the humidity changes in the geological medium. It is worth noting that conducting analysis of the risk zones is based only on the geophysical results.

Generally, It can be said that the area in the dam forefield is very active, when it comes to issues of the water flow. In the discussed case, the CCR and GPR methods provide valuable insight because the GPR measurements (125 MHz and $70 \mathrm{MHz}$ antenna) were performed several days apart. In turn, the ERT measurement was carried out over 20 days after the CCR readings. Both methods show that the electromagnetic properties of the medium are changing over time, which proves that the water flow in the studied area is currently very active and it tends to change.

At first glance, the ERT results suggest that the water flow in this area may be connected with the fault for $\mathrm{x}=90 \mathrm{~m}$, where the developing erosion process found its way for the underground water flow along the fault planes. Hence, it is highly probable that the "L5" sandstone is saturated, which suggests the resistivity value. Reasons why the mentioned sandstone is saturated, can be picked out a few. First of all, it can be connected with the water flow through the slope area from the Szyndzielnia pick (what is possible based on the performed geological settings analysis). Next, the surface water infiltrates into the ground and next finds the way through the fault planes. The assumption is confirmed 
indirectly by the developing submission process at the slope and logging the changing water level in the piezometers. On the other hand, the presented hypothesis is disproved by the fact the water level in the piezometers system is rising even without precipitation in this very area. So, the second reason, which explains the water presence in the ground behind the dam construction, is the water flow under the dam constructed in the body of the highly fractured sandstone and the faults planes. On the other hand, the following hypothesis does not explain why the suffusion zones appear in the slope. Therefore, the most probable theory is that water presence is connected with the two early mentioned factors. The water flows the Szyndzielnia pick and enhances the developing suffusion process in the dam forefield. In the next step water flows down and saturated the fractured sandstone. At once, during the new water flows to the dam reservoir, connected with the precipitation in the nearby mountains, causes increasing water mase in the reservoir, which infiltrated through the flysch reservoir bed and the water is expressed on the other side of the dam. The all mentioned variables compound the dam technical condition.

To sum up, In connection with the above, the most probable main risk zone for the dam is the area where $x=40 m$ to $x=70 m, x=80 m$ to $x=118 m$ and $x=117 m$ to $x=128 m$ of the profile length.

In profile 2, only the GPR and ERT readings were conducted. The mentioned circumstances are connected with the fact that accessibility to the area is limited. it is worth emphasizing that the above-mentioned area has not been transformed by humans, as was the case with the area at profile 1.

The ERT method indicates that the "H1" and "H3" anomaly lie practically below the ground surface. The anomalies are characterized by the resistivity value from $600 \Omega \mathrm{m}$ to $6000 \Omega \mathrm{m}$. Based on the available information about the Carpathian flysch [54], in the studied area, the high resistivity anomalies should be interpreted as the sandstone blocks. The "H3" anomaly, located $6 \mathrm{~m}$ below the ground surface and it is also sandstone in the blocky form.

The relatively low resistivity anomaly (green color), characterized by the resistivity value about $250 \Omega \mathrm{m}$. Similar to profile 1, the anomaly may be interpreted as the yellow and yellow-grey highly fractured sandstone. This assumption is indirectly confirmed by the results of the GPR method, where the GPR method recorded the high-amplitude anomaly.

In the case of the water flow in the P2 area, the ERT method suggests that the "L1" zone $(x=33$ to $x=68 \mathrm{~m})$ may be where water flows down from the Szyndzielnia slope, and this phenomenon decreases the registered resistivity value. This fact confirmed the high-amplitude anomaly identified using the GPR method. In addition, applying the mixed pole GPR methodology enabled the identification of underground channels for depths between 1 and $5 \mathrm{~m}$, depending on the type of antenna orientation used. The ERT was only

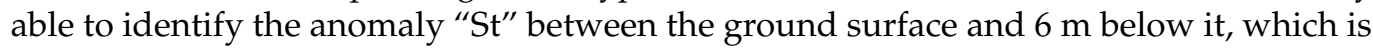
most likely for this kind of underground structure. This seems to be confirmed, because at the " $\mathrm{St}$ " structure end, the very low anomaly, " $\mathrm{L} 0$ ", is spotted, which is connected with the water saturation. It is also probable that " $\mathrm{L} 0$ " anomaly is the inversion process artefact $[29,34]$, which in practice means that near the high resistivity anomalies, the low resistivity anomalies may appear and vice versa. However, in this case the anomaly should be connected with the water flow, which indicates the GPR results.

In the matter of our results comparison with the other papers in the similar topic. We do not find any literature references that described the issue of the water flow/leakage from a dam located within the Carpathian flysch belt. We are also not able to find paper showing leakage propagation with the use of fault planes. Nevertheless, there are a lot of publications about geomorphic hazards in the mentioned region e.g., [54-57]. As an example, can be enumerate landslides, suffusion process, water erosion which is connected directly with the study area.

In the case of applied the geophysical method to detect a potential leakage zones from a dam construction. In the shown examples the most frequently used method is Electrical Resistivity Tomography [58-63]. With the use of the ERT, the paper's authors were able 
to find leaks in the strict vicinity of a dam. In most cases, the anomaly has a relatively low resistivity character. In the papers, we noticed that the 4D ERT tomography is also applied $[64,65]$. In the shown case this approach was also efficient, but it was realized by comparing the ERT and CCR data. Other geophysical methods (GPR, seismic, CCR) are used less frequently but in our case it's allowed to limit the interpretation ambiguity.

Additionally, based on the performed measurements we can provide a very initial methodology that may turn out to be optimal in the matter of the leakage identification. First of all, the general physical properties in the medium should be recognized. It can be realized by applying the ERT method and seismic method. The methods allow to recognize the medium with the proper depth of investigation and also are sensitive to the difference in physical parameters like resistivity and the waves speed. Next step should be connected with the detailing of the studied area. It can be provided by applying the GPR method. Additionally, the method decides if the medium is water filled or contains clay. Probably the best way to catch the area of water flow is to apply 4D ERT.

In turn the CCR method can be applied as the method to recognize medium along the profiles with the bigger length. The method should be checked in more cases as far as it is comparable with the ERT method.

General conclusions are shown in the next section.

\section{Conclusions}

The applied geophysical methods were utilized over the subject area to build a detailed model of the physical properties distribution which was transformed into a geological model in order to find a way of the water flow.

The applied wide spectrum of geophysical methods characterized by different depths of investigation, vertical and horizontal resolution and sensitivity for other physical parameters reduced the interpretation ambiguity and ensured a more reliable geological model.

For the parallel profile line (1) to Szyndzielnia slope, three main geophysical/geological layers were identified. The first layer, the shallowest one, should be interpreted as clay partly mixed with weathered diluvial sediments. Additionally, this layer is porous and saturated with water.

The second layer is not continuous, containing faulted, blocky sandstone. Any ambiguity of interpretation regarding the location and presence of the faults was limited by adopting the seismic method. Additionally, the performed research indicated that the water flows are mainly concentrated in the faults plane for $x=90 \mathrm{~m}$. The water level in this area is very changeable, which is proved by the GPR and ERT results which were performed at different times. It is worth noting that the water from the second layer flows to the third layer mainly through the faults system and is connected with the sandstone cracks. The main reason that the construction is damaging is the fact that water also flows under the dam and then is expressed through the fault plane in sandstone layers. The mentioned phenomena is especially active during the high water level in the reservoir, when the water mass is pressing through the faulted flysch bed and then it is manifested through the increasing water level in the piezometers.

In the center part of the perpendicular profile line (2), a zone with high water permeability was detected, which is the main route for water flowing from the Szyndzielnia peak. Additionally, due to the non-standard antennae orientation in the GPR method, the underground paths of water flows were detected. The ERT method was able to detect only one of these.

In general, the studied area is very active from the point of view of underground water migration. The best method to observe changes in this matter is to conduct $4 \mathrm{D}$ geophysical measurements (monitoring) in the chosen profiles. It is worth noting that the ERT, CCR and GPR methods, all of which were applied at different times, showed that this methodology can be successful in terms of studies of underground water flow.

From a methodical point of view it was noted that the main findings from this work show that a single sledgehammer blow and the use of 26 geophones is potentially sufficient 
to achieve the depth of boundary " $\mathrm{B}$ " (layer 2-3). If a higher resolution is required, the higher signal spectrum should be exploited and a source such as a Betsy gun, shotgun or small portable vibrator should be used. Note that the same acquisition setup can also independently provide the seismic data for the MASW-a method and, as well for the classic MASW which is not examined in this paper.

The next step of research is planning to conduct more geophysical measurements to create a more detailed model of the dam forefield. Assumedly, it allows a better way to recognize the fault system.

Author Contributions: Conceptualization, T.G., B.P., A.B. and M.Ć.; methodology, T.G., B.P., A.B. and M.Ć.; software, T.G., B.P., A.B. and M.Ć.; validation, T.G., M.Ć., B.P. and A.B.; formal analysis, T.G., B.P., A.B. and M.Ć.; investigation, T.G., B.P., A.B. and M.Ć.; resources, T.G., B.P., A.B. and M.Ć.; data curation, T.G., B.P., A.B. and M.Ć.; writing-original draft preparation, T.G., M.Ć., B.P. and A.B.; writing-review and editing, T.G., M.Ć., A.B. and B.P.; visualization, T.G., M.Ć., A.B. and B.P.; supervision, T.G., B.P., A.B. and M.C..; project administration, T.G., M.C.., B.P. and A.B.; funding acquisition, T.G., M.C.., A.B. and B.P. All authors have read and agreed to the published version of the manuscript.

Funding: This research was funded by the grant EMMA (i.e., E-Mobility, sustainable MAterials and Technologies), no. PPI/APM/2018/1/00027/U/001-task no. 9, within cooperation between the Cracow University of Technology (Poland) and the Ecole Centrale de Lille (France); the project was supported by the Polish National Agency for Academic Exchange research program. The works were also supported by the "Poli Doctus" scholarship as part of the project: POWER-“A Way to Perfection-a comprehensive university support program".

Institutional Review Board Statement: Not applicable.

Informed Consent Statement: Not applicable.

Data Availability Statement: The data is available in the disk archive at the Department of Geoengineering and Water Management at the Faculty of Environmental and Power Engineering at the Krakow University of Technology and is not available outside.

Acknowledgments: The work presented in this paper is performed in the framework of the grant EMMA (i.e., E-Mobility, sustainable MAterials and Technologies), no. PPI/APM/2018/1/00027/U/001task no. 9, within cooperation between the Cracow University of Technology (Poland) and the Ecole Centrale de Lille (France); the project was supported by the Polish National Agency for Academic Exchange research program. We also appreciate to "Poli Doctus" scholarship as part of the project: POWER-“A Way to Perfection-a comprehensive university support program".

Conflicts of Interest: The authors declare no conflict of interest.

\section{References}

1. Gasiorowski, S. Budowa Ziemnych Wałów Przeciwpowodziowych, a Stablizacja Gruntu; Kwartalnik kosztorysanta: Warszawa, Poland, 2012.

2. Cracow University of Technology. Technical Report of Department of Water Engineering and Management at the Faculty of Environmental and Power Engineering at the Cracow University of Technology; Cracow University of Technology: Kraków, Poland, 2019.

3. Oboza, K. Budowa i Modernizacja Zapory Wodnej w Wapienicy; Wydawnictow Naukowe Akademii Techniczno-Humanistycznej w Bielsku-Białej: Bielsko-Biała, Poland, 2020.

4. Oboza, K. Budowa i Modernizacja Zapory Wodnej w Wapienicy_Część III. Czasopismo Energetyka Wodna, 2. 2020; $28-32$.

5. Available online: www.ai360.pl/panoramy/391 (accessed on 1 October 2021).

6. Gołebiowski, T. Application of the GPR Method for Detection and Monitoring of Objects with Sochastical Distribution in the Geological Medium; AGH-UST Ed.: Kraków, Poland, 2012.

7. Gołebiowski, T.; Małysa, T. The Application of GPR Method for Detection of Loose Zones in Flood Levee. In Proceedings of the E3S Web of Conferences, Kraków, Poland, 12-13 September 2018; Volume 30.

8. Gołębiowski, T. Changeable-offset GPR Profiling for Loose Zones Detection in the Levees. In Proceedings of the Near Surface Conference, Cracow, Poland, 17 September 2008.

9. Gołęiowski, T. Velocity Analysis in the GPR Method for Loose Zones Detection in the River Embankments. In Proceedings of the International GPR Conference, Lecce, Italy, 21-25 June 2010.

10. Marcak, H.; Gołębiowski, T. The Use of GPR Attributes to Map a Weak Zone in a River Dike. Explor. Geophys. 2014, 45, 125-133. [CrossRef] 
11. Marcak, H.; Gołębiowski, T.; Tomecka-Suchon, S. Analysis of Possibility of Using the GPR Refraction for Location Changes in River Embankments. Geology 2005, 31, 259-274.

12. Gołebiowski, T.; Piwakowski, B.; Ćwiklik, M. Application of the GPR and ERT Methods for Non-invasive Examination of Flood Dike. In Proceedings of the Scientific and Technical Conference MATBUD, Cracow, Poland, 19-21 October 2020.

13. Gołębiowski, T.; Tomecka-Suchoń, S.; Farbisz, J. Application of Complex Geophysical Metods for Non-invasive Examination of Technical Conditions of Flood Dikes. In Proceedings of the European Symposium on Anti-flood Defences, Paris-Orleans, France, 28-30 March 2012.

14. Royet, R.; Palma-Lopes, S.; Fauchard, C.; Mériaux, P.; Auriau, L. Reliability of Urban Flood Defences—Rapid and Cost-Effective Dike Condition Assessment Methods: Geophysics and Remote Rensing; FloodProBE-Project Report of Grant Agreement no: 243401; HAL: Orléans, France, 2013.

15. Łój, M.; Porzucek, S.; Gołębiowski, T.; Everett, M.E. Microgravimetric and GPR Surveys for Detection of Unconsolidated Zones in a Levee. In Proceedings of the E3S Web of Conferences, Cracow, Poland, 28-29 June 2018; Volume 66.

16. Ezersky, M.; Eppelbaum, L. Geophysical monitoring of underground constructions and its theoretical basis. Int. J. Georesources Environ. 2017, 3, 56-72. [CrossRef]

17. Fauchard, C.; Mériaux, P. Geophysical and Geotechnical Methods for Diagnosing of Flood Protection Dikes; Cemagref Éditions: Saint Berthevin, France, 2007.

18. Bestyński, Z. Geophysical investigations to hydraulic engineering purposes. Geology 2009, 35, $292-403$.

19. ReflexW. User Guide; Sandmeier Geophysical Research Ed.: Karlsruhe, Germany, 2019.

20. Annan, A.P. Practical Processing of GPR Data; Sensor \& Software: Mississauga, ON, Canada, 1999.

21. Annan, A.P. Ground Penetrating Radar; Sensor \& Software Ed.: Ontario, ON Canada, 2001.

22. Yilmaz, Ö. Seismic Signal Processing: Society of Exploration Geophysicists; Series: Investigation in Geophysics, Volume I; Michael, R.C., Ed.; Society of Exploration Geophysicists: Tulsa, OK, USA, 1987.

23. Daniels, J.J.; Wielopolski, L.; Radzevicius, S.; Bookshar, J. 3D GPR Polarization Analysis for Imaging Complex Objects. In Proceedings of the 16th SAGEEP Conference, San Antonio, TX, USA, 6 April 2003.

24. Radzevicius, S.J.; Daniels, J.J. Ground penetrating radar polarization and scattering from cylinders. J. Appl. Geophys. 2000, 45, 111-125. [CrossRef]

25. Roberts, R.L.; Daniels, J.J. Analysis of GPR Polarization Phenomena. J. Environ. Eng. Geophys. 1996, 1, 139-157. [CrossRef]

26. Roberts, R.R. Analysis and Theoretical Modeling of GPR Polarization Data. Ph.D. Dissertation, The Ohio State University, Columbus, OH, USA, 1994.

27. Ensted, D.B.; Dahlin, D.; Danielsen, J.E. Model Study of the Resolution of Resistivity Tomography with Different Electrode Arrays. In Proceedings of the Near Surface 2005-11th European Meeting of Environmental and Engineering Geophysics, Palermo, Italy, 4-7 September 2005.

28. Dahlin, T.; Zhou, B.A. Numerical Comparison of 2D Resistivity Imaging with Ten Electrode Arrays. Geophys. Prospect. 2004, 52, 379-398. [CrossRef]

29. Loke, M.H. 2-D and 3-D Electrical Imaging Surveys; Tutorial Geotomo Software: Penang, Malaysia, 2003.

30. Loke, M.H. Rapid 2D Resistivity E IP Inversion Using Least-Squares Method; Tutorial Geotomo Software: Penang, Malaysia, 2010.

31. Szalai, S. About The Depth Of Investigation Of Different D.C. Dipole-Dipole Arrays. Acta Geod. Et Geophys. Hung. 2000, 35, 63-73.

32. Szalai, S.; Szarka, L. An approximate analytical approach to compute geoelectric dipole-dipole responses due to a small buried cube. Geophys. Prospect. 2000, 48, 871-885. [CrossRef]

33. GF Instruments, Geophysical Equipment and Services. Available online: www.gfinstruments.cz (accessed on 1 October 2021).

34. Loke, M.H.; Ackworth, I.; Dahlin, T. A comparison of smooth and blocky inversion methods in $2 \mathrm{D}$ electrical imaging surveys. Explor. Geophys. 2003, 34, 182-187. [CrossRef]

35. Demirci, I.; Erdoğan, E.; Candansayar, M.E. Two-dimensional inversion of direct current resistivity data incorporating topography by using finite difference techniques with triangle cells: Investigation of Kera fault zone in western Crete. Geophysics 2012, 77, E67-E75. [CrossRef]

36. Erdoğan, E.; Demirci, I.; Candansayar, M.E. Incorporating topography into 2D resistivity modeling using finite-element and finite-difference approaches. Geophysics 2008, 73, F135-F142. [CrossRef]

37. Fox, R.C.; Hohmann, G.W.; Killpack, T.J.; Rijo, L. Topographic effects in resistivity and induced-polarization surveys. Geophysics 1980, 45, 75-93. [CrossRef]

38. Günther, T.; Rücker, C.; Spitzer, K. Three-dimensional modeling and inversion of DC resistivity data incorporating topography-II. Inversion. Geophys. J. Int. 2006, 166, 506-517. [CrossRef]

39. Penz, S.; Chauris, H.; Donno, D. Resistivity modeling with topography. Geophys. J. Int. 2013, 194, 1486-1497. [CrossRef]

40. Ball, L.B. Capacitively Coupled Average Resistivity of the Interstate and Tri-State Canals; Scientific Investigations Report; U.S. Geological Survey: Lincoln, NE, USA, 2006; p. 5032.

41. Garman, K.M.; Purcell, S.F. Applications for capacitively coupled resistivity surveys in Florida. Lead. Edge 2004, $23,697-698$. [CrossRef]

42. Aspinall, A.; Saunders, M.K. Experiments with the square array. Archaeol. Prospect. 2005, 12, 115-129. [CrossRef]

43. Papadopoulos, N.G.; Tsourlos, P.; Tsokas, G.N.; Sarris, A. Two-dimensional and three-dimensional resistivity imaging in archaeological site investigation. Archaeol. Prospect. 2006, 13, 163-181. [CrossRef] 
44. Kuras, O.; Beamish, D.; Meldrum, P.I.; Ogilvy, R.D. Fundamentals of the capacitive resistivity technique. Geophysics 2006, 71, G135-G152. [CrossRef]

45. Telford, W.M.; Geldart, L.P.; Sheriff, R.E. Applied Geophysics, 2nd ed.; Cambridge University Press: Cambridge, UK, 1990.

46. Timofeev, V.M.; Rogozinski, A.W.; Hunter, J.A.; Douma, M. A new ground resistivity method for engineering and environmental geophysics. In Proceedings of the 7th EEGS Symposium on the Application of Geophysics to Engineering and Environmental Problems, Boston, MA, USA, 27 March 1994; pp. 701-715.

47. OhmImager Manual, OhmImager Software for Data Analysis of the OhmMapper, Version 1.1; Geomatrics: San Jose, CA, USA, 2014.

48. Ghose, R.; Nijhof, V.; Brouwer, J.; Matsubara, J.; Kaida, Y.; Takahashi, T. Shallow to very shallow high-resolution reflection seismic using a portable vibrator system. Geophysics 1998, 63, 1295-1309. [CrossRef]

49. Piwakowski, B. From high resolution land seismic imaging to very high resolution: State of the art, limits and field examples. Invited paper special HRS session. In Proceedings of the International Symposium of European Association of Exploration Geophysicists, Paris, France, 6-10 June 2004.

50. Knapp, R.W.; Steeples, D.W. High resolution common-depth-point seismic reflection profilling: Field acquisition parameter design. Geophysics 1986, 51, 283-294. [CrossRef]

51. Piwakowski, B. Underground voids mapping by high resolution seismic reflection: Limits, accuracy and assessment of collapse risk. In Proceedings of the International Symposium of European Association of Exploration Geophysicists, Paris, France, 6-10 June 2004.

52. WinSeisbSeismic Reflection Software. Available online: www.kgs.ku.edu/software/winseis/index.html (accessed on 1 October 2021).

53. Foti, S.; Lai, C.G.; Glenn, J.; Strobbia, C. Surface Wave Methods for Near-Surface Site Characterization; CRC Press: Boca Raton, FL, USA, 2015.

54. Starkel, L. Rozwój Rzeźby Polskich Karpat Fliszowych w Holocenie; PAN 22; Prace Geograficzne IG: Warsaw, Poland, 1960; 239p.

55. Saramka, A. Ekstremalne Opady Atmosferyczne i Ich Potencjalny Wpływ na Wybrane Procesy Stokowe na Przykładzie GaikaBrzezowej. Ph.D Thesis, Climatological Section of Institute of Geography, Jagiellonian University, Kraków, Poland, 2005.

56. Selby, M.J. Dominant geomorphic events in landform evolution. Bull. Int. Assoc. Eng. Geol. 1974, 9, 85-89. [CrossRef]

57. Starkel, L. Charakterystyka rzeźby Polskich Karpat i jej znaczenie dla gospodarki ludzkiej. Probl. Zagospod. Ziemi Górskich 1972, 10, 75-150.

58. Adagunodo, T.A.; Sunmonu, L.A.; Ojoawo, A.; Oladejo, O.P.; Olafisoye, E.R. The Hydro Geophysical Investigation of Oyo State Industrial Estate Ogbomosho, Southwestern Nigeria Using Vertical Electrical Soundings. Res. J. Appl. Sci. Eng. Technol. 2013, 5, 1816-1829. [CrossRef]

59. Adagunodo, T.A.; Sunmonu, L.A.; Adeniji, A.A. Effect of Dynamic Pattern of the Saprolitic Zone and its Basement on Building Stability: A Case Study of a High-Rise Building in Ogbomoso. J. Appl. Phyical Sci. Int. 2015, 3, 106-115.

60. Adagunodo, T.A.; Adeniji, A.A.; Erinle, A.V.; Akinwumi, S.A.; Adewoyin, O.O.; Joel, E.S.; Kayode, O.T. Geophysical Investigation into the Integrity of a Reclaimed Open Dumpsite for Civil Engineering Purpose. Intciencia J. 2017, 42, 324-339.

61. Akinwumi, I.I. Soil Modification by the Application of Steel Slag. Period. Polytech. Civ. Eng. 2014, 58, 371-377. [CrossRef]

62. Cho, I.K.; Yeom, J.Y. Crossline resistivity tomography for the delineation of anomalous seepage pathways in an embankment dam. Geophysics 2007, 72, 31-38. [CrossRef]

63. Kim, J.H.; Yi, M.J.; Song, Y.; Seol, S.J.; Kim, K.S. Application of geophysical methods to the safety analysis of an earth dam. J. Environ. Eng. Geophys. 2007, 12, 221-235. [CrossRef]

64. Johanssonand, S.; Dahlin, T. Seepage monitoring in an earth embankment dam repeated resistivity measurements. Eur. J. Environ. Eng. Geophys. 1996, 1, 229-247.

65. Sjodahl, P.; Dahlin, T.; Johansson, S. Using resistivity measurements for dam safety evaluation at Enemossen tailings dam in southern Sweden. Environ. Geol. 2005, 49, 267-273. [CrossRef] 